\title{
GABAergic activities control spike timing- and frequency- dependent long-term depression at hippocampal excitatory synapses
}

\author{
Makoto Nishiyama $^{1 *}$, Kazunobu Togashi ${ }^{1}$, Takeshi Aihara ${ }^{2}$ and Kyonsoo Hong ${ }^{1 *}$ \\ 1 Department of Biochemistry, New York University School of Medicine, New York, NY, USA \\ 2 Department of Information-Communication Engineering, Tamagawa University, Tokyo, Japan
}

\section{Edited by:}

Henry Markram, Ecole Polytechnique

Federale de Lausanne, Switzerland

\section{Reviewed by:}

Takao Hench, Harvard University, USA Shigeru Kubota, Yamagata University, Japan

Yoshiyuki Kubota, National Institute for Physiological Sciences, Japan

\section{*Correspondence:}

Makoto Nishiyama, Department of Biochemistry, New York University School of Medicine, New York, NY, 10016, USA.

e-mail: nishim01@nyumc.org; Kyonsoo Hong, Department of Biochemistry, New York University School of Medicine, New York, NY, 10016, USA.

e-mail: hongk02@nyumc.org
GABAergic interneuronal network activities in the hippocampus control a variety of neural functions, including learning and memory, by regulating $\theta$ and $\gamma$ oscillations. How these GABAergic activities at pre- and postsynaptic sites of hippocampal CA1 pyramidal cells differentially contribute to synaptic function and plasticity during their repetitive pre- and postsynaptic spiking at $\theta$ and $\gamma$ oscillations is largely unknown. We show here that activities mediated by postsynaptic GABA $A_{A}$ s and presynaptic $G_{A B A} A_{B}$ ss determine, respectively, the spike timingand frequency-dependence of activity-induced synaptic modifications at Schaffer collateral-CA1 excitatory synapses. We demonstrate that both feedforward and feedback GABA ${ }_{A}$ R-mediated inhibition in the postsynaptic cell controls the spike timing-dependent long-term depression of excitatory inputs ("e-LTD") at the $\theta$ frequency. We also show that feedback postsynaptic inhibition specifically causes e-LTD of inputs that induce small postsynaptic currents $(<70 \mathrm{pA})$ with LTPtiming, thus enforcing the requirement of cooperativity for induction of long-term potentiation at excitatory inputs ("e-LTP"). Furthermore, under spike-timing protocols that induce e-LTP and e LTD at excitatory synapses, we observed parallel induction of LTP and LTD at inhibitory inputs (" $i$-LTP" and " $i$ LTD") to the same postsynaptic cells. Finally, we show that presynaptic $\mathrm{GABA}_{\mathrm{B}} \mathrm{R}$-mediated inhibition plays a major role in the induction of frequency-dependent $e$-LTD at $\alpha$ and $\beta$ frequencies. These observations demonstrate the critical influence of GABAergic interneuronal network activities in regulating the spike timing-and frequency-dependences of long-term synaptic modifications in the hippocampus.

Keywords: STDP, CA1, GABA, spike timing, frequency, hippocampal oscillation

\section{INTRODUCTION}

GABAergic interneuronal network activities regulate a variety of neural functions, such as modulation of activity-dependent synaptic plasticity (Meredith et al., 2003), i.e., long-term potentiation (LTP) and depression (LTD), and serve as a driving force for the hippocampal $\theta$ and $\gamma$ oscillations important for processing learning and memory (Buzsáki, 2002; Csicsvari et al., 2003; Lisman et al., 2005). GABA functions as a major inhibitory neurotransmitter at both excitatory (glutamatergic) and inhibitory (GABAergic) neurons in the central nervous system by activating $G_{A B A}$ receptors $\left(\mathrm{GABA}_{\mathrm{A}} \mathrm{Rs}\right)$ and $\mathrm{GABA}_{\mathrm{B}}$ receptors $\left(\mathrm{GABA}_{\mathrm{B}} \mathrm{Rs}\right)$ in both pre- and postsynaptic cells (Connors et al., 1988; Davies and Collingridge, 1996). However, the inhibitory function of GABA on postsynaptic $\mathrm{GABA}_{\mathrm{A}} \mathrm{Rs}$ depends on the state of the $\mathrm{Cl}^{-}$ion reversal potential relative to the resting membrane potential (Staley et al., 1995). For example, in the hippocampus, GABAergic inhibition induced by stimuli at the $\alpha / \beta$ (low, $10 \mathrm{~Hz}$ ) frequency shifts to excitation when stimuli occur at the $\gamma$ (high, $40 \mathrm{~Hz}$ ) frequency as a consequence of intracellular $\mathrm{Cl}^{-}$ion $\left(\left[\mathrm{Cl}^{-}\right]_{i}\right)$ accumulation in postsynaptic CA1 pyramidal cells (Staley et al., 1995; Bracci et al., 2001). In addition, GABA inhibition through presynaptic $\mathrm{GABA}_{\mathrm{B}} \mathrm{Rs}$, which are linked to G-protein-coupled inwardly rectifying $\mathrm{K}^{+}$channels (GIRK), imposes different frequency dependencies at excitatory and inhibitory presynaptic terminals that are effective, respectively, above the $\alpha / \beta$ frequency (Ohliger-Frerking et al., 2003) and near the $\theta$ frequency (Davies and Collingridge, 1996).

In hippocampal neural networks, different populations of GABAergic interneurons (Maccaferri et al., 2000; Klausberger and Somogyi, 2008) contribute to postsynaptic feedforward (FF) and feedback (FB) inhibition at CA1 pyramidal cells (Pouille and Scanziani, 2001, 2004) and to presynaptic inhibition at excitatory and inhibitory presynaptic terminals to CA1 pyramidal cells. However, it is unknown how these distinct GABA actions affect excitatory synaptic gains, either differentially or synergistically. Depending on the precise timing of pre- and postsynaptic neuronal spikes, repetitive spiking reliably induces either LTP or LTD, collectively known as spike-timing-dependent plasticity (STDP), in hippocampal neurons in culture (Bi and Poo, 1998; Debanne et al., 1998), in hippocampal or cortical neurons in slices (Markram et al., 1997; Feldman, 2000; Nishiyama et al., 2000; Sjöström et al., 2001; Froemke and Dan, 2002; Woodin et al., 2003), and in neurons of the tectum in vivo (Zhang et al., 1998). Previously, we showed that at hippocampal Schaffer collateral (SC)-CA1 pyramidal cell excitatory synapses, STDP induced by stimuli at $5 \mathrm{~Hz}$ ( $\theta$ frequency) is composed of two distinct LTD time intervals (-LTD: -28 to $-16 \mathrm{~ms}$ and +LTD: +15 to $+20 \mathrm{~ms})$ that flank an LTP time interval $(-2$ to 
+15 ms) (Nishiyama et al., 2000). Interestingly, this LTP/LTD time interval cycle is completed within $25 \mathrm{~ms}$ at $40 \mathrm{~Hz}$ ( $\gamma$ frequency), similar to the time course of the $\gamma$ oscillation in vivo (Csicsvari et al., 2003), which hippocampal GABAergic interneuronal networks are believed to regulate (Whittington et al., 1995; Bartos et al., 2007; Cardin et al., 2008; Sohal et al., 2008). Also, repetitive stimuli at SC inputs persistently alter synaptic efficacy at GABAergic inputs to CA1 pyramidal cells (Woodin et al., 2003; Chevaleyre and Castillo, 2004; Lamsa et al., 2005; Gibson et al., 2008). We, therefore, monitored synaptic efficacy at CA1 pyramidal cells to investigate how these dynamic patterns of GABAergic interneuronal inputs regulate spike timing- and frequency-dependent STDP at excitatory synapses (e-STDP).

\section{MATERIALS AND METHODS HIPPOCAMPAL SLICE PREPARATION}

Hippocampal slices were prepared by a standard procedure (Nishiyama et al., 2000). Male Sprague-Dawley rats (26- to 35-day old) were anaesthetized and decapitated. Right hippocampi were dissected rapidly and placed in a gassed $\left(95 \% \mathrm{O}_{2}-5 \% \mathrm{CO}_{2}\right)$ extracellular solution containing (in $\mathrm{mM}$ ) $124 \mathrm{NaCl}, 3 \mathrm{KCl}, 2.6 \mathrm{CaCl}_{2}$, $1.3 \mathrm{MgSO}_{4}, 1.25 \mathrm{NaH}_{2} \mathrm{PO}_{4}, 22 \mathrm{NaHCO}_{3}$ and $10 \mathrm{D}$-glucose at $10^{\circ} \mathrm{C}$. Transverse slices of $500-\mu \mathrm{m}$ thickness were cut with a rotor tissue slicer (Dosaka, DTY7700) and maintained at room temperature $\left(23-26^{\circ} \mathrm{C}\right)$ in an incubation chamber for at least $2 \mathrm{~h}$. For experiments, individual slices were transferred to a submersion recording chamber and perfused continuously with extracellular solution $(4.0 \sim 4.5 \mathrm{ml} / \mathrm{min})$ at room temperature. Experiments using a $\mathrm{K}^{+}$-based internal recording solution (see below) were performed at $30-33^{\circ} \mathrm{C}$. To prevent epileptiform activity, the CA3 region was removed in experiments that used GABA and muscarinic receptor antagonists.

\section{WHOLE-CELL RECORDING}

Whole-cell recordings were made in the CA1 cell body layer with the "blind" patch clamp method, using an Axopatch 200B amplifier (Axon Inst.). Test stimuli were applied at $0.05 \mathrm{~Hz}$ and alternated between two non-overlapping SC inputs using bipolar electrodes (MCE-100, RMI) under voltage-clamp $\left(V_{c}=-80 \mathrm{mV}\right)$ [except when inhibitory postsynaptic currents (IPSCs) were measured] to evoke excitatory postsynaptic currents (EPSCs). Both stimulating electrodes were positioned at the stratum radiatum at least $500 \mu \mathrm{m}$ distant from the recording electrode to avoid stimulation of monosynaptic (direct) inhibitory inputs. The non-overlap of the two inputs was confirmed by applying alternate paired-pulse test stimuli (at 50-ms intervals) to demonstrate the absence of cross facilitation between the two inputs. Constant current pulses (amplitude, 6-14 $\mu \mathrm{A}$; duration, $300 \mu \mathrm{s}$ ) evoked EPSCs with amplitudes of 100-200 pA. These current intensities were at least three fold smaller than the stimulation currents that evoke population spikes. Following a stable recording period of about $12\left(\mathrm{~K}^{+}\right.$-based internal recording solution) or $15\left(\mathrm{Cs}^{+}\right.$-based internal recording solution) $\mathrm{min}$, the recording was switched to current clamp and a train of stimuli at a frequency of $5 \mathrm{~Hz}$ was delivered to one of the two inputs for either $20 \mathrm{~s}$ ( $\mathrm{K}^{+}$-based) or $16 \mathrm{~s}\left(\mathrm{Cs}^{+}\right.$-based). Each presynaptic stimulus was paired with the injection of a spike-form ( $\mathrm{K}^{+}$-based: $2 \mathrm{nA}$ for $2 \mathrm{~ms}$ at the peak, $\left.I_{\max }\right)$ or square $\left(\mathrm{Cs}^{+}\right.$-based: $2 \mathrm{nA}$ for $2 \mathrm{~ms}$ ) depolarizing current pulse into the postsynaptic neuron to initiate spiking at various time intervals. The spike-form depolarizing currents $(t$ in $\mathrm{ms}): I_{\max } \cdot 10 \cdot t, 0 \leq t<0.1 ; I_{\max }, 0.1 \leq t<2.1$; $I_{\max } \cdot\left[(1-(0.8 / 1.5) \cdot(t-2.1)], 2.1 \leq t<3.6 ; I_{\max } \cdot[0.2-(0.12 / 2) \cdot(t-3.6)]\right.$, $3.6 \leq t<5.6 ; I_{\max } \cdot 0.08 \cdot[1-(1 / 2.5) \cdot(t-5.6)], 5.6 \leq t<8.1$ were designed to reduce the jitter of postsynaptic spikes but not to affect the spike decay time. Depolarization-induced suppression of inhibition (DSI) was induced by changing $V$ from -80 to $0 \mathrm{mV}$ for $2-3 \mathrm{~s}$, followed by the application of the spike-timing protocol (at 5-, 12- and $25-\mathrm{Hz}$ for 16, 6.7 and $3.2 \mathrm{~s}$, respectively) for various time intervals after 5-10 s. A voltage-step of $+90 \mathrm{mV}$ from the holding potential (at $-80 \mathrm{mV}$ ) was applied for $40 \mathrm{~ms}$ every $60 \mathrm{~s}$ to visualize feedforward (FF)-IPSCs during the concurrent monitoring of EPSC/FF-IPSC. A 40 -ms voltage-step was chosen to avoid the induction of DSI (estimated to be less than 1\% according to Lenz and Alger, 1999) but was long enough to detect peak currents of disynaptic FF-IPSCs. During this voltage-step, EPSC was masked because the commanding potential (i.e., $+10 \mathrm{mV}$ ) was approximately equivalent to the EPSC reversal potential. The identity of FF-IPSC was confirmed as a result of its abolition by bath-applied gabazine $(10-100 \mu \mathrm{M})$ and kynurenic acid ( $5 \mathrm{mM}$ ). Data were filtered at $2 \mathrm{kHz}$ and digitized at $10 \mathrm{kHz}$. Patch electrodes were pulled from borosilicate glass $(1.2-\mathrm{mm}$ O.D.) and had a resistance of 3.5 6 M $\Omega$. Pipettes were filled with a solution containing (in $\mathrm{mM}$ ): $120 \mathrm{~K}$-gluconate, $10 \mathrm{KMeSO}_{3}, 10$ $\mathrm{KCl}$, 0.075 BAPTA, 20 HEPES, 4 Mg-ATP, $2 \mathrm{Na}$-ATP, $\mathrm{pH}$ adjusted to 7.35 with $\mathrm{KOH}$. For experiments that required sustained postsynaptic depolarization, a $\mathrm{Cs}^{+}$-based internal solution was used that contained (in mM): 130 cesium methanesulphonate $(\mathrm{CsMeSO})$, 10 tetraethylammonium (TEA) chloride $\left(\mathrm{Cl}^{-}\right), 0.25$ 1,2-bis (2-aminophenoxy)ethane-N,N,N'N'-tetraacetic acid (BAPTA), $10 \mathrm{~N}$-[1hydroxyethyl]-piperazine- $\mathrm{N}^{\prime}$-[2-ethanesulphonic acid] (HEPES), $2 \mathrm{Mg}$-ATP, $2 \mathrm{Na}_{2}$-ATP, $\mathrm{pH}$ adjusted to 7.35 with $\mathrm{CsOH}$,. The series resistance (typically 10-14 M $\Omega$ ) was compensated $50-80 \%$ and was monitored throughout the experiment using a $-5 \mathrm{mV}$ step command. Cells that showed an unstable series resistance ( $>20 \%$ changes after the spike-timing protocol) were not used. To monitor monosynaptic IPSCs, $40 \mu \mathrm{M}$ CNQX and $50 \mu \mathrm{M}$ D(-)-2-amino-5phosphonovaleric acid (AP5) were present in the extracellular solution and $\mathrm{CsCl}$ instead of $\mathrm{CsMeSO}_{3}$ was used intracellularly while the cells were held at $-70 \mathrm{mV}$. Drugs (bicuculline, kynurenic acid, gabazine, CNQX, AP5 and phaclofen) were purchased from either RBI or Tocris. CGP35348 was a generous gift from Novartis.

\section{RESULTS}

\section{SINGLE, PRE- AND POSTSYNAPTIC SPIKING AT THE $\theta$ FREOUENCY RECRUITS BOTH FEEDFORWARD AND FEEDBACK POSTSYNAPTIC GABA R-MEDIATED INHIBITION}

We performed whole-cell recordings at CA1 pyramidal cells in hippocampal slices (Figure 1A) in which the GABAergic networks are well defined (Figure 1B) (Maccaferri et al., 2000; Pouille and Scanziani, 2001, 2004; Klausberger and Somogyi, 2008). We stimulated SC inputs in the stratum radiatum at 100-150 $\mu \mathrm{m}$ away from the stratum pyramidale (SP, somatic layer) to evoke both EPSCs and FF-IPSCs in $500 \mu \mathrm{m}$ thick slices. We used a CsMeSO ${ }_{3}^{-}$ based ( $\mathrm{Cs}^{+}$-based) internal solution, which blocks GIRKs, to isolate the effects of postsynaptic $\mathrm{GABA}_{\mathrm{A}} \mathrm{R}$-mediated inhibition from those of postsynaptic $\mathrm{GABA}_{\mathrm{B}} \mathrm{R}$-mediated inhibition. In this 
A

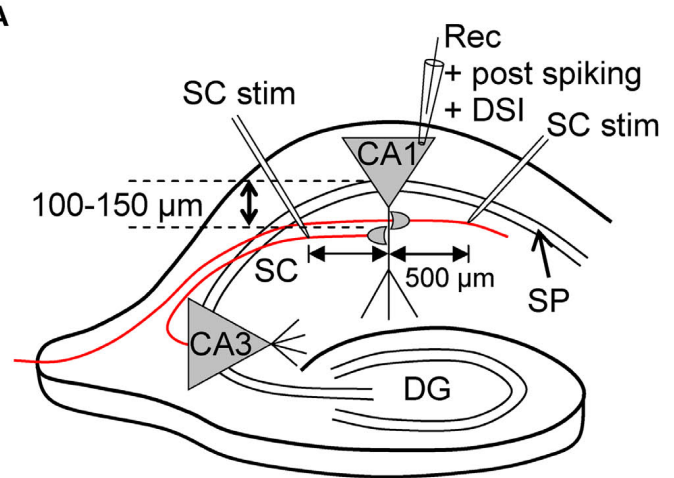

C
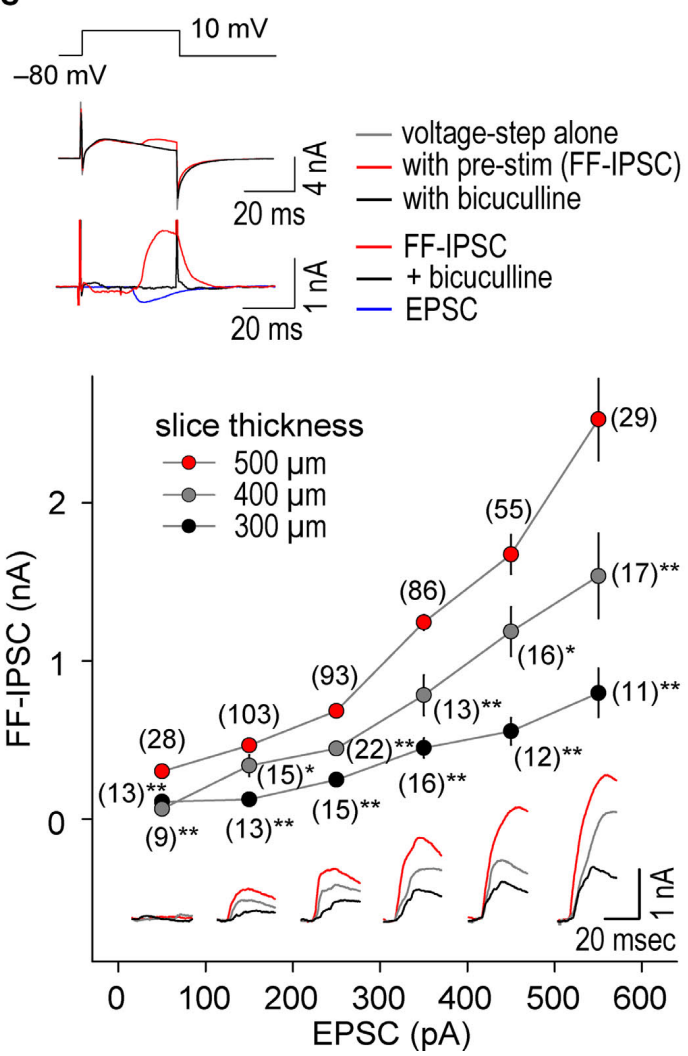

FIGURE 1 | Repetitive, single pre- and postsynaptic spiking recruits both FF and $F B$ postsynaptic GABA $A_{A}$-mediated inhibition in hippocampal $C A 1$ pyramidal cells. (A) Experimental paradigm depicting the positions of stimulating and recording electrodes. Whole-cell recordings were made in the CA1 cell body and the test stimuli were applied at the stratum radiatum at least $500 \mu \mathrm{m}$ distant from the recording electrode. (B) Schematic diagram of neuronal networks involved in the induction of STDP in CA1 pyramidal cells. Locations of excitatory (e) and inhibitory (I) inputs and GABA receptors are indicated. (C) Procedure for concurrent measurement of EPSCs and FF-IPSCs (top) and summary of their amplitudes (bottom). FF-IPSC is detected (top middle) with the use of voltagesteps (top upper) and presynaptic stimulation (pre-stim). The magnitude of FF-IPSC (top lower, black) is calculated by subtracting the voltage-step alone (top middle, black) from the pre-stimulation value (top middle, blue). The voltage-step at $+10 \mathrm{mV}$ was applied for $40 \mathrm{~ms}$ to prevent the induction of DSI (less than 1\%; Lenz and Alger, 1999). The FF-IPSC was confirmed by GABA $A_{A}$ blockade with bicuculline ( $20 \mu \mathrm{M}$, top middle and lower, red). The ratio of FF-IPSCs to EPSCs increased as the slice thickness increased. Data represent the mean EPSC/FF-IPSC ( \pm sem).
B

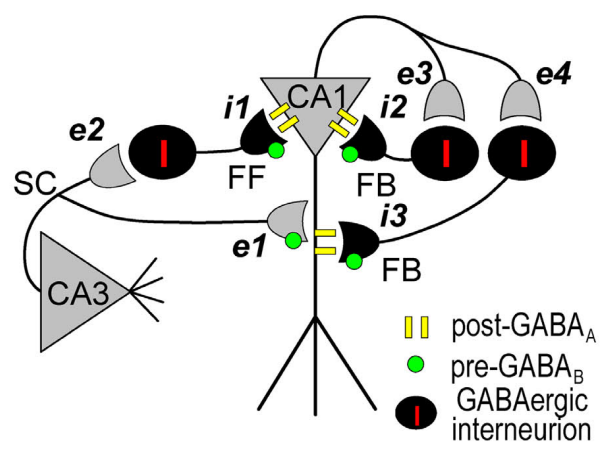

D

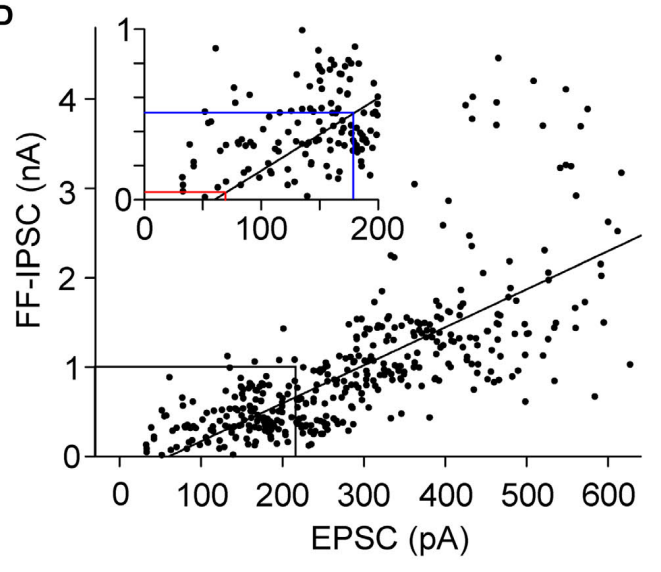

E

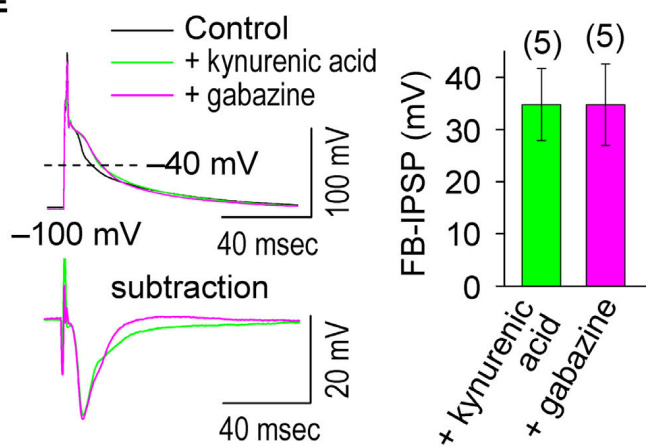

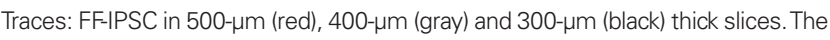
(number) indicates the total number of trials. Significant differences from corresponding data in 500- $\mu \mathrm{m}$ thick slices are indicated ("* " $p<0.05$ and "**" $p<0.01$; Mann-Whitney $\mathrm{U}$ test). (D) The amplitude of FF-IPSC is proportional to the EPSC amplitude. When the EPSC level is $<70 \mathrm{pA}$, there is no FF-IPSC (see red line in inset). The EPSC amplitude normally used in this study is indicated (blue line in inset). (E) Prominent FB postsynaptic $\mathrm{GABA}_{\mathrm{A}} \mathrm{R}$-mediated inhibition is recruited by repetitive $5-\mathrm{Hz}$ postsynaptic spiking in $\mathrm{CA} 1$ pyramidal cells. Postsynaptic spiking was induced by depolarizing current injections $(6 \mathrm{nA}, 2 \mathrm{~ms}, 20$ pulses at $5 \mathrm{~Hz}$ ) while postsynaptic CA1 pyramidal cells were held at $-100 \mathrm{mV}$ in a current-clamp configuration using a $\mathrm{Cs}^{+}$-based internal recording solution. The top left panel shows the postsynaptic membrane potentials monitored when FB postsynaptic $\mathrm{GABA}_{\mathrm{A}} \mathrm{R}$-mediated inhibition was blocked by either kynurenic acid $(5 \mathrm{mM})$ or gabazine $(10 \mu \mathrm{M})$. The control, in which $\mathrm{GABA}_{\mathrm{A}} \mathrm{R}$ was not blocked, showed a feedback inhibition-inclusive membrane potential. Subtraction analysis (bottom left) revealed a membrane potential resulting from FB postsynaptic $\mathrm{GABA}_{\mathrm{A}} \mathrm{R}$-mediated inhibition. Average FB-IPSP (right). 
configuration, we found that substantially more GABAergic inputs relative to glutamatergic inputs were retained than in thinner (300 and $400 \mu \mathrm{m}$ ) slices (Figure 1C); the FF-IPSC amplitude was $1045 \pm 44 \mathrm{pA}$ when the EPSC amplitude was $301 \pm 8 \mathrm{pA}( \pm \mathrm{sem}$, $n=408$; differences between commanding and reversal potentials were ca. $90 \mathrm{mV}$ for both FF-IPSCs and EPSCs) (Megias et al., 2001). Consistent with the idea that monosynaptic EPSCs and disynaptic FF-IPSCs normally share the same population of SC inputs in our experimental paradigm, the magnitudes of both EPSCs and FF-IPSCs changed in positive correlation with the magnitudes of presynaptic stimuli at SC inputs (Figures 1C,D). Weak, superlinearly- increased FF-IPSC amplitudes, greater than those of EPSCs, were observed when strong stimuli were applied to SC inputs (i.e., EPSC amplitudes $>300$ pA; Figure 1D, bottom). This superlinearity, the mechanism for which is unknown, may help to facilitate the failure of LTP induction at strong inputs, which has been demonstrated in cultured hippocampal neurons (Bi and Poo, 1998) and is believed to maintain gain levels of the entire network activity (van Rossum et al., 2000). It is noteworthy that as presynaptic stimulation was decreased, FF-IPSCs disappeared at a level at which EPSCs of $\sim 70 \mathrm{pA}$ remained (see Figure 1D inset), indicating that $e$-STDP can be examined in the absence of functional FF-IPSCs to individually-recorded pyramidal cells.

To ascertain whether $\mathrm{FB}$ postsynaptic $\mathrm{GABA}_{\mathrm{A}} \mathrm{R}$-mediated inhibition occurred during the $\theta$ frequency $(5 \mathrm{~Hz}$ ) spike-timing protocol, we injected postsynaptic spike-inducing depolarizing currents ( $6 \mathrm{nA}$ for $2 \mathrm{~ms}$ ) through the whole-cell recording electrodes for 20 pulses (at $5 \mathrm{~Hz}$ ) in the absence of presynaptic stimuli. The recorded cell was held at $-100 \mathrm{mV}$ under the current clamp to avoid sustained depolarization after spikes in the absence of $\mathrm{K}^{+}$channel function. Feedback postsynaptic $\mathrm{GABA}_{\mathrm{A}} \mathrm{R}$-mediated membrane hyperpolarization was measured as differential potentials in which the spike afterpotential (averaged between the 15th and 20th spikes) in the presence of either gabazine $(10-100 \mu \mathrm{M})$, a GABA $\mathrm{A}_{\mathrm{A}}$ antagonist, or kynurenic acid ( $5 \mathrm{mM}$ ), a glutamate receptor antagonist (to eliminate disynaptic responses), was subtracted from that in the absence of antagonists (Figure 1E). We observed a FB postsynaptic GABA $_{\mathrm{A}}$ R-mediated hyperpolarizing effect of ca. $-34 \mathrm{mV}$ when cell membrane potentials were at ca. $-40 \mathrm{mV}$, demonstrating the occurrence of functional FB postsynaptic $\mathrm{GABA}_{\mathrm{A}} \mathrm{R}$-mediated inhibition. Thus, our experimental paradigm is a unique method to investigate differential GABAergic effects (e.g., pre- vs. postsynaptic, $\mathrm{GABA}_{A} \mathrm{R}$ - vs. $\mathrm{GABA}_{\mathrm{B}} \mathrm{R}$-mediated and FF vs. FB) on the induction of $e$-STDP.

\section{$e$-STDP INDUCED AT THE $\theta$ FREQUENCY IS INDEPENDENT OF

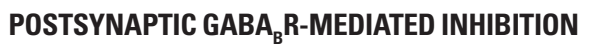

Blocking postsynaptic $\mathrm{K}^{+}$channel activity, including that linked to $\mathrm{GABA}_{\mathrm{B}} \mathrm{R}$ function, may also affect the spike-timing dependence of $e$-STDP. We, therefore, examined the timing-dependent feature of $e$-STDP using a K-gluconate-based (control) internal solution in the recording pipette. We applied SC stimulation that evoked EPSCs of amplitude $>70 \mathrm{pA}$ to ensure the presence of functional FF-IPSCs (Figure 1D). When presynaptic stimuli at SC-CA1 synapses were paired with postsynaptic spike-inducing depolarizing currents with a time interval of $+5 \mathrm{~ms}$ at $5 \mathrm{~Hz}$ for $20 \mathrm{~s}$, we observed input-specific e-LTP (Figure 2A), which was comparable to that induced by a 16-s spike-timing protocol (at positive time interval) in the $\mathrm{Cs}^{+}$-based internal solution (Figure 2A). That a comparable LTP was induced is likely attributable to the fact that activated postsynaptic sites were close enough to the soma to receive backpropagating action potentials due to the absence of prominent A-type $\mathrm{K}^{+}$channel activity (Hoffman et al., 1997). These conditions permit repetitive, single pre- and postsynaptic spiking to induce $e$-LTP (Nishiyama et al., 2000).

We also compared the postsynaptic spike wave forms during the LTP-timing protocol in the $\mathrm{Cs}^{+}$-based internal solution with those in the $\mathrm{K}^{+}$-base internal solution (Figure 2B). In the $\mathrm{Cs}^{+}$-based internal solution, the spikes evoked by the postsynaptic depolarizing currents were ca. 50\% broader (half-maximal width of $3.1 \pm 0.3 \mathrm{~ms}, n=18$ ) than in the $\mathrm{K}^{+}$-based solution. However, this spike width is noticeably smaller than that reported previously in thinner $(300 \mu \mathrm{m})$ slices (Wittenberg and Wang, 2006). Moreover, membrane potential changes recorded in the postsynaptic cell during the LTP-timing protocol were stably maintained, even when the $\mathrm{Cs}^{+}$-based internal solution was used, in 500- $\mu \mathrm{m}$ thick slices (Figure 2C). In contrast, a strong depolarization was observed when we applied the same spike-timing protocol in thinner (i.e., $300-\mu \mathrm{m}$ thick) slices or slices $(500-\mu \mathrm{m}$ thick) treated with $20 \mu \mathrm{M}$ bicucullin, which eliminated postsynaptic $\mathrm{GABA}_{\mathrm{A}} \mathrm{R}$-mediated inhibition (Figure 2C). Collectively, the observations of relatively small spike width and stable postsynaptic membrane potential in the $\mathrm{Cs}^{+}$-based internal solution support the presence of prominent postsynaptic $\mathrm{GABA}_{\mathrm{A}} \mathrm{R}$-mediated inhibition that accelerated spike after-repolarization.

We systematically examined the spike-timing dependence of $e$-STDP at the $\theta$ frequency. As shown in Figure 2D, we observed two distinct time windows for the induction of $e$-LTD, -31 to $-18 \mathrm{~ms}$ (-LTD) and +18 to $+34 \mathrm{~ms}$ ( + LTD), that flanked single time intervals of +3 to $+9 \mathrm{~ms}$ for the induction of $e$-LTP. Moreover, the induction of $e$-LTD for both negative and positive time intervals at activated synapses was associated with heterosynaptic $e$-LTD at non-activated synapses. Although a broader time window for +LTD (20 ms duration) was observed in the $\mathrm{K}^{+}$-based internal solution, the timing dependence of this $e$-STDP was similar to that in the $\mathrm{Cs}^{+}$-based internal solution (in the absence of postsynaptic $\mathrm{GABA}_{\mathrm{B}} \mathrm{R}$-mediated inhibition, Figure 2D; modified from Nishiyama et al., 2000 by the addition of new data points). This suggests that postsynaptic GABA $_{B}$ R-mediated inhibition-linked GIRKs and other $\mathrm{K}^{+}$channel activities, including that of A-type $\mathrm{K}^{+}$channels, are not essential determinants of the spike-timing dependence of $e$-STDP induced at the $\theta$ frequency.

\section{POSTSYNAPTIC GABA R-MEDIATED INHIBITION CONTROLS THE SPIKE-TIMING DEPENDENCE OF $\boldsymbol{e}$-LTD}

The induction of STDP depends on the pattern of postsynaptic $\mathrm{Ca}^{2+}$ elevation (Magee and Johnston, 1997; Nishiyama et al., 2000; Sjöström and Nelson, 2002; Dan and Poo, 2006; Nevian and Sakmann, 2006; Caporale and Dan, 2008), which results from interactions between dendritic back-propagating action potentials and excitatory postsynaptic potentials (EPSPs) (Koester and Sakmann, 1998; Schiller et al., 1998; Stuart and Häusser, 2001). Since dendritic action potentials are regulated by FF and FB postsynaptic GABA $_{\mathrm{A}}$ R-mediated inhibition (Buzsáki et al., 1996; Tsubokawa and 


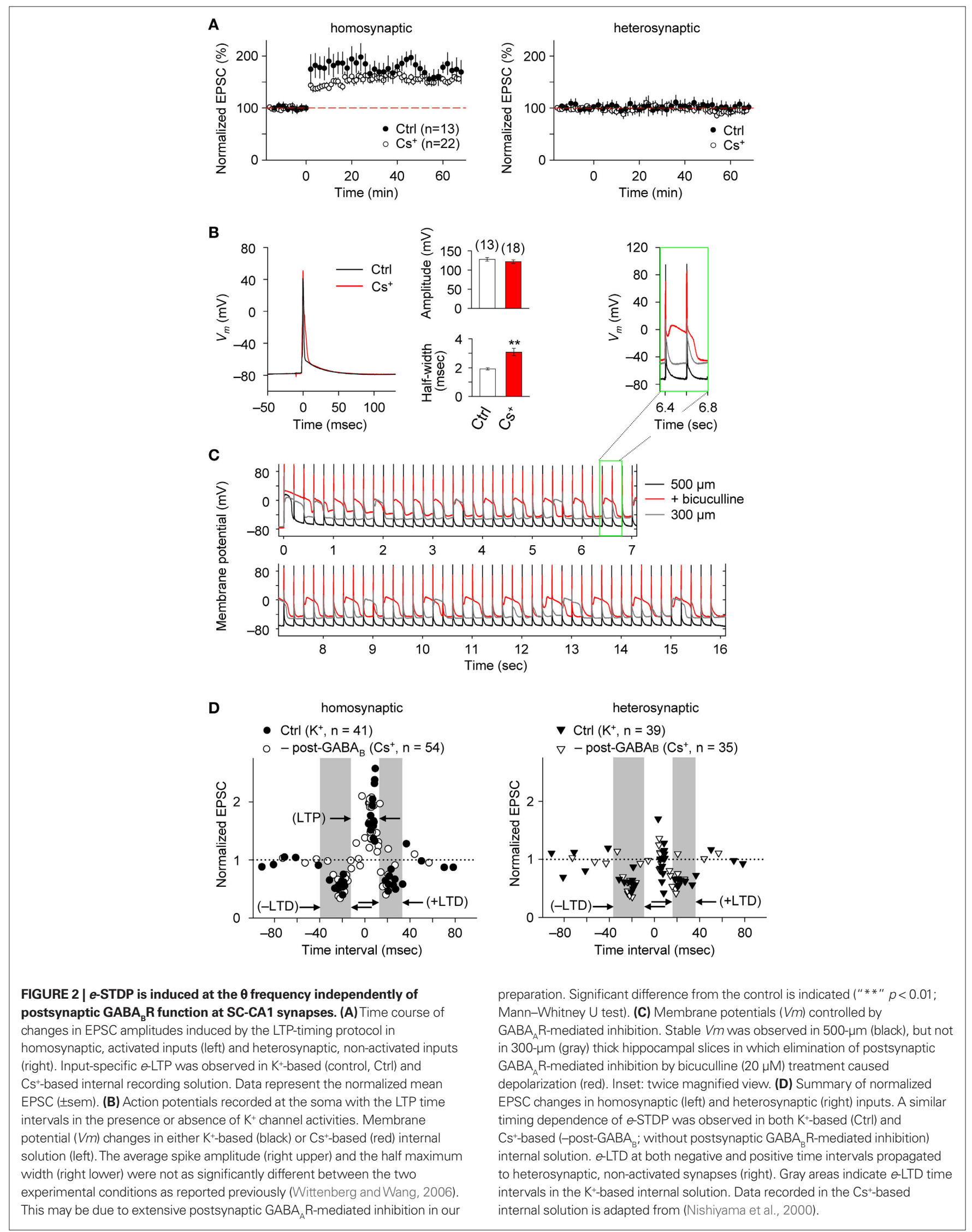


Ross, 1996; Pouille and Scanziani, 2001), we examined whether postsynaptic $\mathrm{GABA}_{\mathrm{A}} \mathrm{R}$-mediated inhibition affects the spike-timing dependence of $e$-STDP induced at the $\theta$ frequency. We first investigated the impact of postsynaptic $\mathrm{GABA}_{\mathrm{A}} \mathrm{R}$-mediated inhibition on the induction of $e$-LTD (-LTD; Figure 2D), in the $\mathrm{K}^{+}$-based internal solution as a control. To eliminate postsynaptic $\mathrm{GABA}_{\mathrm{A}} \mathrm{R}$-mediated inhibition, gabazine $(5 \mu \mathrm{M})$, a GABA $\mathrm{R}$ antagonist (Pouille and Scanziani, 2004), was administrated in the bath a few minutes before the spike-timing protocol and remained throughout the $e$-LTD induction protocol. As shown in Figure 3A, e-LTD was abolished in the presence of gabazine, demonstrating that $\mathrm{GABA}_{\mathrm{A}} \mathrm{R}$ activity is required for the induction of $e$-LTD. To confirm that postsynaptic $\mathrm{GABA}_{\mathrm{A}} \mathrm{R}$-mediated membrane hyperpolarization was responsible for the $e$-LTD induction, the recorded cells were held at $-85 \mathrm{mV}$ (in current clamp) while postsynaptic $\mathrm{GABA}_{\mathrm{A}} \mathrm{R}$-mediated inhibition was blocked by bath-applied gabazine. The reversal potential of $\mathrm{GABA}_{\mathrm{A}} \mathrm{R}$ was $-73.8 \pm 3.1 \mathrm{mV}(n=4)$, when the $\mathrm{Cs}^{+}$-based internal solution was used. Application of hyperpolarizing currents to the recorded cells restored the induction of $e$-LTD, which, unlike in the control, was expressed immediately after the spike-timing

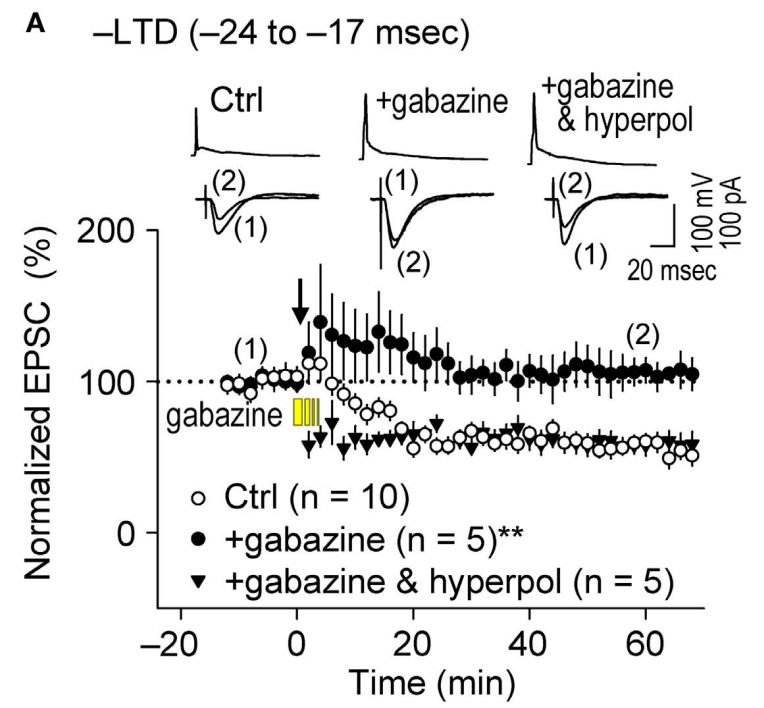

C $-\operatorname{LTD}(-24$ to $-22 \mathrm{msec})$

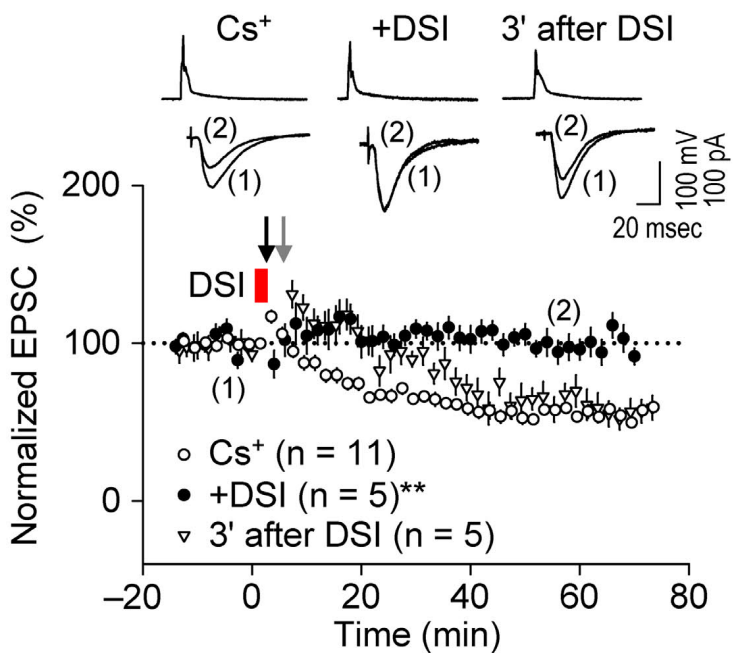

FIGURE 3 | Postsynaptic GABA ${ }_{A}$ R-mediated inhibition controls the spike-timing dependence of $e$-LTD at the $\theta$ frequency. (A) Bath application of gabazine ( $5 \mu \mathrm{M}$, yellow bars) abolished e-LTD (time intervals: -24 to $-17 \mathrm{~ms}$ ), whereas hyperpolarization (hyperpol) of postsynaptic cells restored e-LTD. (B) Brief postsynaptic depolarization (arrow; dep, 3 s) induced DSI at SC inputs. (C) DSI (red bar) induction immediately preceding the spike-timing protocol (black arrow) abolished e-LTD (time intervals: -24 to $-22 \mathrm{~ms}$ ), whereas DSI applied 3 min before
B

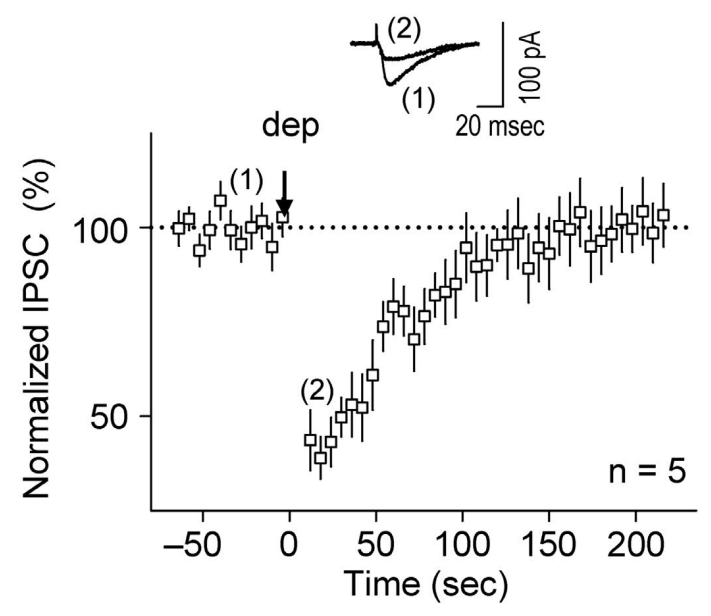

D

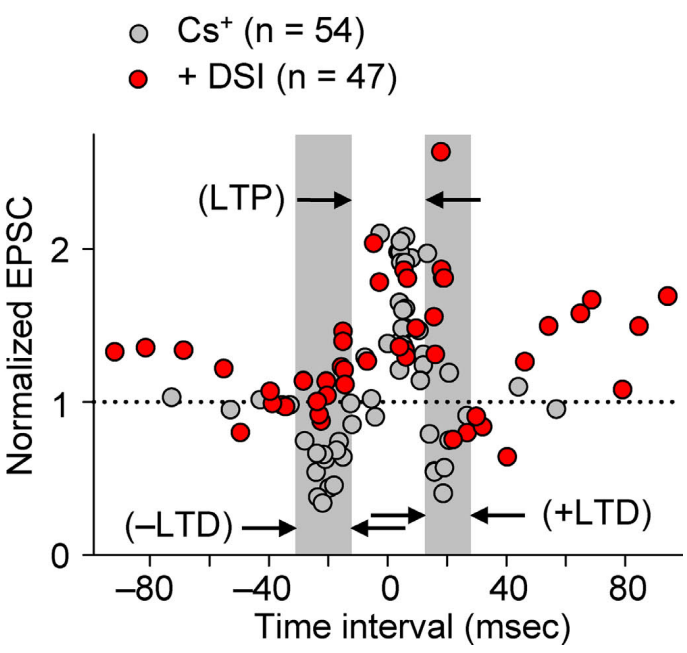

(gray arrow) had no effect on the e-LTD. Data represent normalized mean EPSCS/ IPSCs ( \pm sem). Sample traces of membrane potentials during the spike-timing protocol (top, in $\mathbf{A}, \mathbf{C}$ ) and of IPSCs (in B)/EPSCs (bottom, in $\mathbf{A}, \mathbf{C}$ ) before (1) and after (2) the induction protocols. Significant differences from corresponding controls are indicated (“**” $p<0.01$; Mann-Whitney U test). (D) Summary of time windows for e-STDP in the presence (filled red circle) and absence (filled gray circle) of DSI. Gray areas show LTD time intervals in the absence of DSI. 
protocol (Figure 3A). The slow onset of $e$-LTD in the presence of GABA $\mathrm{R}$ function may be due to robustly enhanced FF-IPSCs immediately after the spike-timing protocol (see Figure 5C), the FF-IPSC component of which is expected to be $14.5 \pm 0.8 \%$ of the EPSC amplitude $(n=4)$ before the induction protocol.

The bath application of gabazine would eliminate total $\mathrm{GABA}_{\mathrm{A}} \mathrm{R}$ function in hippocampal networks. Therefore, to test the effects of postsynaptic $\mathrm{GABA}_{\mathrm{A}} \mathrm{R}$-mediated inhibition specifically on the recorded cells, we applied the method of depolarization-induced suppression of inhibition (DSI, Lenz and Alger, 1999) by clamping the recorded cell at $0 \mathrm{mV}$ using the $\mathrm{Cs}^{+}$-based internal solution. Since stimulation at the stratum oriens/alveus has been used to demonstrate DSI (Lenz and Alger, 1999), we examined the effects of DSI on IPSCs evoked by stimuli at the stratum radiatum. Application of a 2-3 s depolarization (from -70 to $0 \mathrm{mV}$ ) to the recorded postsynaptic CA1 pyramidal cell induced DSI ( $43 \pm 6 \%$ of the control, $n=5$ ) for about $2 \mathrm{~min}$ (Figure 3B), similarly as previously reported (Lenz and Alger, 1999). In this particular experiment, we applied ca. two to three fold stronger stimuli (amplitude, 20-40 $\mu \mathrm{A}$; duration, $300 \mu \mathrm{s}$ ) to evoke monosynaptic IPSCs of ca. $70 \mathrm{pA}$. When the DSI procedure was applied $5-10 \mathrm{~s}$ before the application of the spike-timing protocol at the $\theta$ frequency, induction of $e$-LTD within the time interval of -24 to $-22 \mathrm{~ms}$ (-LTD) was eliminated (Figure 3C). In contrast, when the DSI procedure was applied 3 min before the same spike-timing protocol, by which time FF-IPSCs should have recovered to normal levels from the DSI (Figure 3B), the induction of $e$-LTD was successfully restored to control levels (Figure 3C). The postsynaptic $\mathrm{Ca}^{2+}$ increase caused by the DSI procedure, which is known to last for only a few seconds (Isokawa and Alger, 2006), is unlikely to have overlapped with that subsequently induced by the spike-timing protocol (applied 5-10 s later).

The effects of DSI on $e$-STDP induced at various time intervals (from -92 to $+94 \mathrm{~ms}$ ) were also examined. As shown in Figure 3D, the DSI did not affect significantly the magnitude of $e$-LTP induced by the LTP-timing protocol (time interval at $+5 \mathrm{~ms}$ ). In contrast, DSI not only eliminated $e$-LTD induction at both the -LTD and + LTD time intervals, but induced the most robust $e$-LTP at the original +LTD time intervals (Figure 3D). This might be due to the induction of higher NMDA receptor-mediated currents that coincided with postsynaptic spikes (Vargas-Caballero and Robinson, 2004). Moreover, reduction of postsynaptic $\mathrm{GABA}_{\mathrm{A}} \mathrm{R}$-mediated inhibition to approximately one half by the DSI resulted in two effects on the STDP time window for $e$-LTP induction: First, the original window of -2 to $+15 \mathrm{~ms}$ was expanded to -15 to $+20 \mathrm{~ms}$, and second, additional LTP time windows appeared at -100 to $-55 \mathrm{~ms}$ and at +45 to $+100 \mathrm{~ms}$ (Figure 3D). This temporal feature of $e$-LTP induction may be consistent with the idea that DSI biases the STDP learning rule toward LTP. In the presence of DSI, we observed two distinct time windows $(-55$ to $-15 \mathrm{~ms}$ and +20 to $+45 \mathrm{~ms}$ ) in which no $e$-LTP could be induced. The absence of $e$-LTP at -55 to -15 ms may have been due to the overlapping slow component of spike afterhyperpolarization, which was sensitive to blockade of inositol 1,4,5-trisphosphate receptors (unpublished data). The current study, however, cannot explain the absence of $e$-LTP (and slight $e$-LTD) at the intervals of +20 to +45 ms. Taken together, these results demonstrate the essential role of postsynaptic $\mathrm{GABA}_{\mathrm{A}} \mathrm{R}$-mediated inhibition as a critical determinant for the timing dependence of the $e$-STDP induction protocol at the $\theta$ frequency.

\section{FEEDBACK POSTSYNAPTIC GABA ${ }_{A}$ R-MEDIATED INHIBITION CAUSES $e$-LTD TO ENFORCE COOPERATIVE $e$-LTP}

As demonstrated above, prominent $\mathrm{FB}$ postsynaptic GABA $\mathrm{R}$ mediated inhibition was induced by $5-\mathrm{Hz}$ postsynaptic spiking (Figure 1E), whereas FF postsynaptic $\mathrm{GABA}_{\mathrm{A}} \mathrm{R}$-mediated inhibition was diminished as the intensity of presynaptic stimulation at SC inputs was reduced to a level that induced EPSCs of amplitudes $<70 \mathrm{pA}$ (red line in Figure 1D inset). We, therefore, examined the effect of FB inhibition on $e$-STDP in the absence of functional FF inhibition by stimulating a smaller population of SC inputs that evoked small EPSCs $(<70 \mathrm{pA})$, using the $\mathrm{Cs}^{+}$-based recording solution. Unexpectedly, we found that the LTP-timing protocol (spiking intervals of +4 to $+6 \mathrm{~ms}$ ) induced $e$-LTD instead of $e$-LTP (Figures 4A,B), consistent with the requirement of cooperativity among multiple, coincident inputs for the induction of $e$-LTP (Bliss and Collingridge, 1993). Moreover, when FB postsynaptic GABA $\mathrm{R}$ mediated inhibition was suppressed by DSI, this $e$-LTD became a robust $e$-LTP, similar to that induced at inputs of amplitudes $>70 \mathrm{pA}$ (Figures 4A,B). Associative $e$-LTP can be induced at a single SC input to CA1 pyramidal cells by the pairing protocol (postsynaptic depolarization to $0 \mathrm{mV}$ with presynaptic stimuli of 200 pulses at $1 \mathrm{~Hz}$ ) in the absence of $\mathrm{GABA}_{\mathrm{A}} \mathrm{R}$-mediated inhibition (Petersen et al., 1998). These results, therefore, suggest that FB postsynaptic $\mathrm{GABA}_{\mathrm{A}} \mathrm{R}$-mediated inhibition not only prevents $e$-LTP induction at LTP time intervals (i.e., enforcing the requirement of cooperativity), but also causes the induction of $e$-LTD (i.e., gating for the induction of $e$-LTD). Similar $e$-LTD induction with the LTP-timing protocol has been reported in layer $\mathrm{V}$ cortical neurons at inputs from layer II/III neurons with stimuli at $50 \mathrm{~Hz}$ (Sjöström and Häusser, 2006). This $e$-LTD induction by a high-frequency $(>50 \mathrm{~Hz})$ protocol may be attributable to the difference of the threshold frequency of the spiking required to evoke $\mathrm{FB}$ postsynaptic $\mathrm{GABA}_{\mathrm{A}} \mathrm{R}$-mediated inhibition in these cortical neurons (Silberberg and Markram, 2007). Thus, this gating function of $e$-LTD by FB inhibition may be a universal rule for $e$-STDP. In contrast, $e$-LTD induction at the negative time intervals (-LTD) did not show this cooperative requirement (Figures 4C,D). An EPSC amplitude of 70 pA normally represents the co-activation of 10-20 synapses, as estimated from the average mini-EPSC amplitude of 3-5 pA (Kato et al., 1994), which may be capable of generating local dendritic $\mathrm{Ca}^{2+}$ spikes (Schiller et al., 2000). Therefore, intricate dendritic processing (e.g., integration or competition) of information according to the learning rule based on local spiking and that based on the back-propagating action potential (Jarsky et al., 2005; Rumsey and Abbott, 2006) may occur during the spike-timing protocol at the $\theta$ frequency.

\section{PARALLEL INDUCTION OF $e$-LTP/i-LTP AND $e$-LTD/i-LTD OCCURS AT $\theta$ FREOUENCY STIMULATION}

It is widely accepted that during the induction of $e$-LTP at SC-CA1 inputs by tetanic stimulation, inhibitory inputs undergo LTD (i-LTD, McMahon and Kauer, 1997; Chevaleyre and Castillo, 2003; Gibson et al., 2008), which is mediated by endocannabinoid signaling (Chevaleyre and Castillo, 2003). Conversely, repetitive 

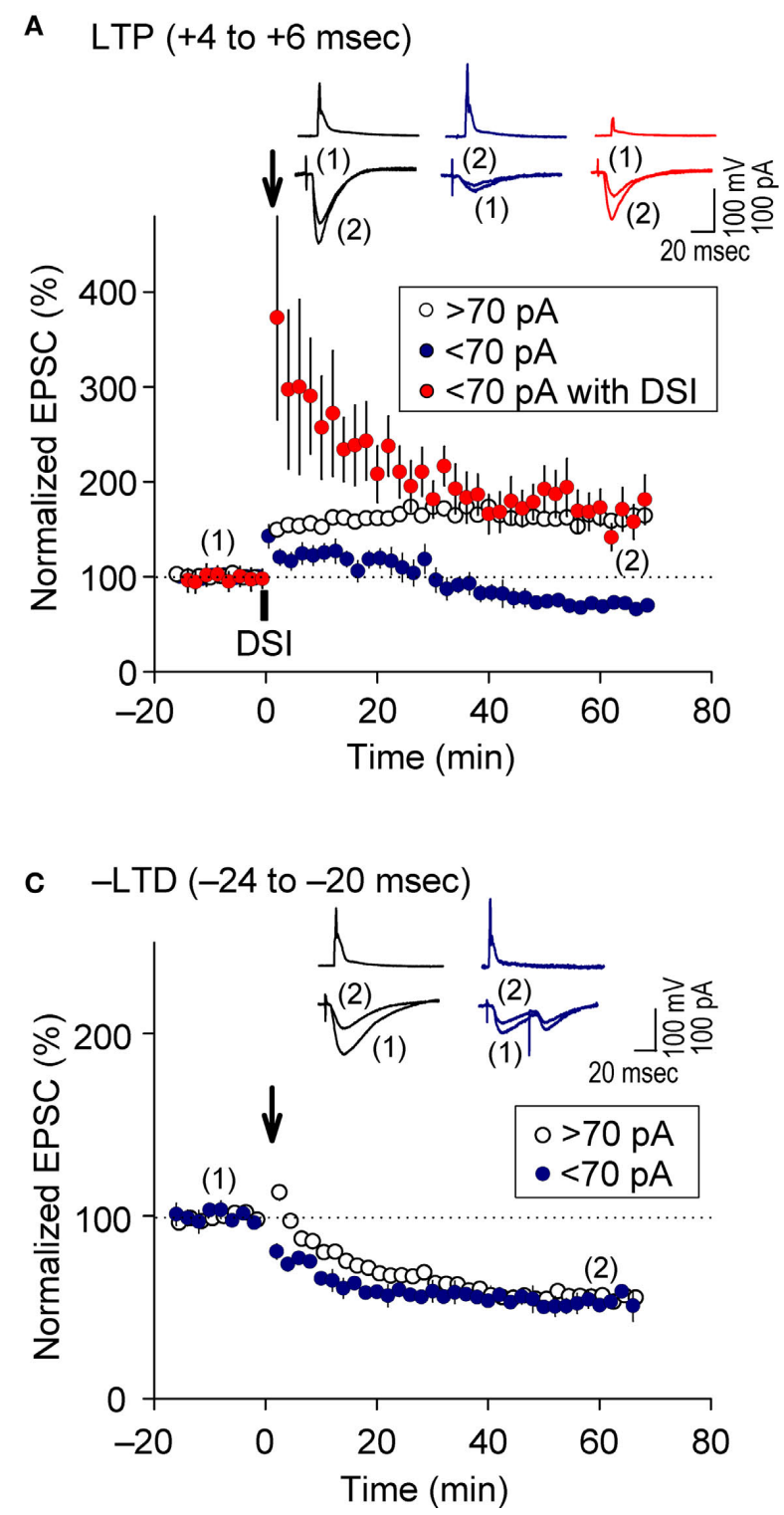

FIGURE 4 | Feedback postsynaptic GABA R-mediated inhibition causes $\boldsymbol{e}$-LTD that enforces the requirement of cooperative $\boldsymbol{e}$-LTP. $(\mathbf{A}, \mathbf{B}) e-L T D$ is induced by the LTP-timing protocol when the initial EPSC amplitudes are $<70 \mathrm{pA}$. DSI converts this e-LTD to e-LTP to the same extent as that induced
B

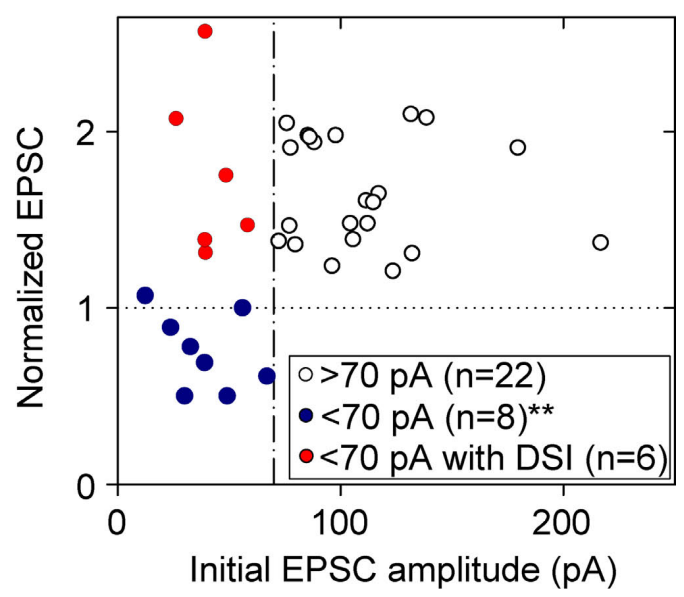

D

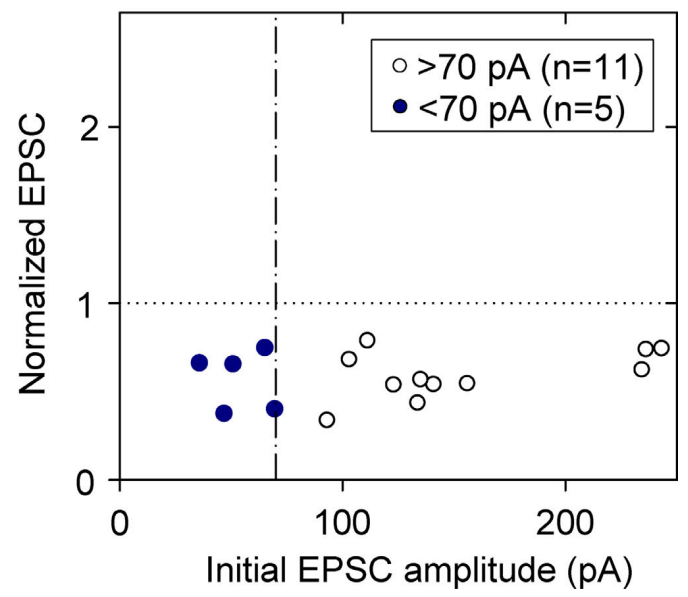

normally at EPSC inputs of amplitude $>70$ pA. (C,D) e-LTD is induced to a similar extent independent of the initial EPSC amplitudes. Significant difference from corresponding controls is indicated (“**” $p<0.01$; MannWhitney $U$ test). presynaptic stimulation, even at relatively low frequency $(10 \mathrm{~Hz})$, induces endocannabinoid-mediated $i$-LTD that facilitates $e$-LTP induction at neighboring synapses (Chevaleyre and Castillo, 2004). Furthermore, the DSI procedure facilitates LTP induction known as endocannabinoid-mediated disinhibition, which requires $50-\mathrm{Hz}$ tetanic stimulation with small numbers of pulses at excitatory synapses (Carlson et al., 2002). We, therefore, examined $i$-STDP induction following application of the $\theta$ frequency spike-timing protocol at excitatory synapses. We concurrently measured EPSCs and FF-IPSCs from the same CA1 pyramidal cells at spiking time intervals for both LTP $(+4$ to $+6 \mathrm{~ms})$ and -LTD $(-24$ to $-20 \mathrm{~ms})$. Stimuli of the same intensity were applied to the same SC inputs to evoke both EPSCs and FF-IPSCs while 40-ms voltage-steps from -80 to $+10 \mathrm{mV}$ (the EPSC reversal potential) were applied to the recorded neurons to monitor FF-IPSCs. This allowed the stable recording of both EPSCs and FF-IPSCs for more than 90 min (Figure 5A). Surprisingly, we found that EPSCs and FF-IPSCs underwent parallel potentiation and depression of similar magnitudes following paired stimulation with spiking intervals that induced $e$-LTP (Figure 5B) and $e$-LTD (Figure 5C), although FF-IPSCs showed extensive short-term potentiation, regardless of the timing of the induction protocol. These results suggest that endocannabinoid-mediated $i$-LTD (Chevaleyre and Castillo, 2004) did not occur following the induction of $e$-LTP 
A

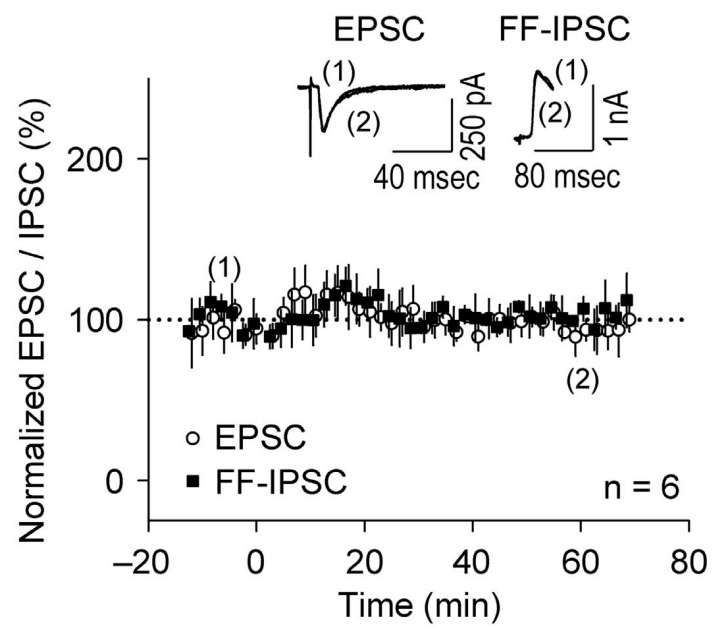

C

$-\operatorname{LTD}(-24$ to $-20 \mathrm{msec})$

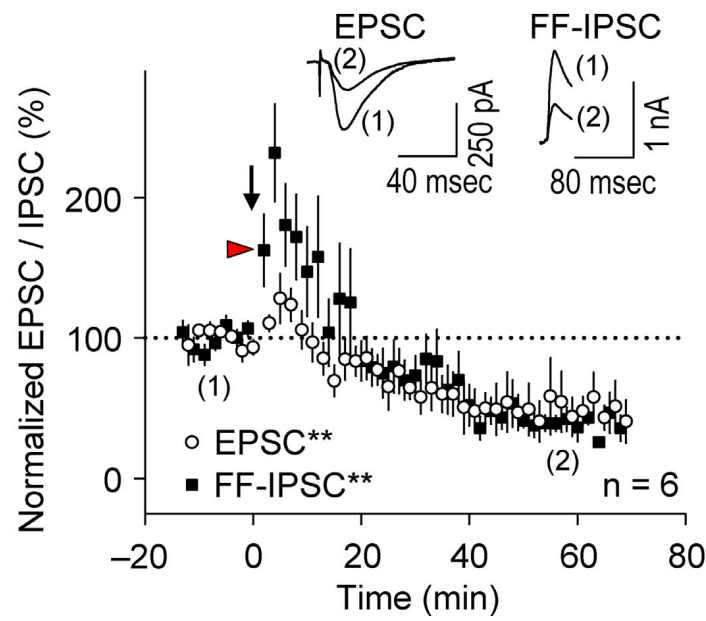

FIGURE 5 | Parallel induction of $e$-LTP/i-LTP and $e$-LTD/ $i$-LTD occurs under prominent postsynaptic GABA $_{A}$ R-mediated inhibition. (A) Normalized EPSC/ FF-IPSC amplitudes (\%) without the spike-timing protocol. No changes in either EPSCs or FF-IPSCs were observed during the time course of the experiments. (B,C) EPSCs and FF-IPSCs were both potentiated at the LTP time intervals (B), and
B

$\operatorname{LTP}(+4$ to +6 msec)

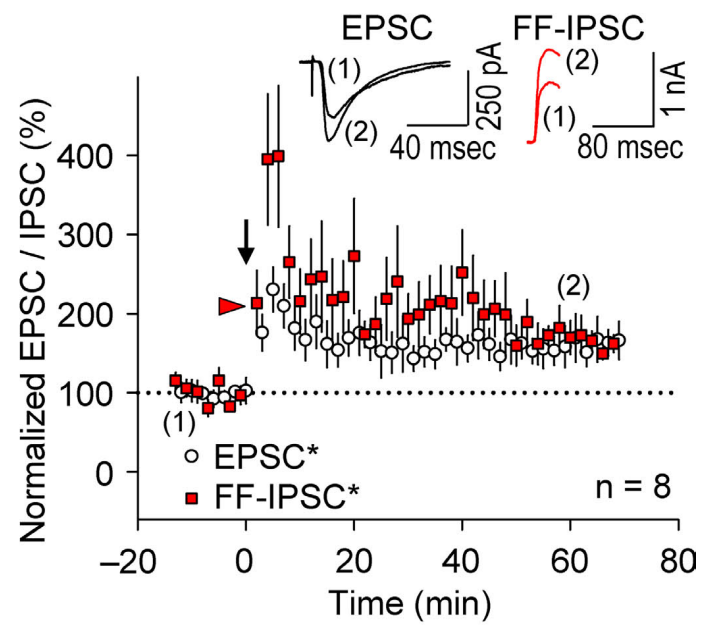

D
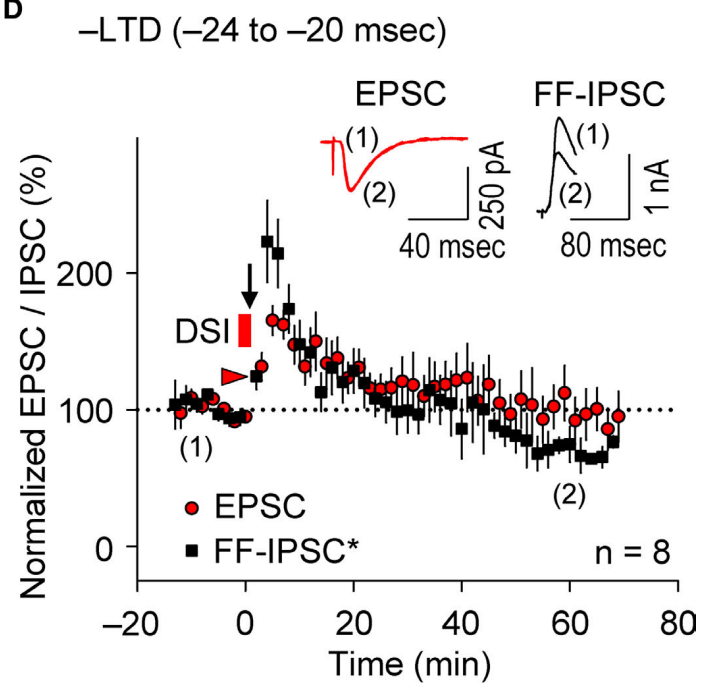

depressed at the -LTD time intervals (C). (D) DSI abolished LTD of EPSC, but not of FF-IPSC at the -LTD time intervals. Data represent normalized mean EPSCS/ FF-IPSCs ( \pm sem). Sample traces of EPSCs/FF-IPSCs (in B-D) before (1) and after (2) the induction protocols. Significant differences from corresponding controls are indicated ("*" $p<0.05$ and "**" $p<0.01$; Mann-Whitney U test).

\section{PRESYNAPTIC GABA ${ }_{B}$ R-MEDIATED INHIBITION CAUSES FREOUENCY-DEPENDENT $e$-LTD}

Presynaptic glutamate release, which determines the EPSC amplitude, would be reduced if the frequency of presynaptic spiking were to increase (Ohliger-Frerking et al., 2003) as a result of activation of G-protein coupled receptors (GPCRs) at presynaptic terminals (Wu and Saggau, 1997). Because GABA $_{B}$ Rs are the major GPCRs at glutamatergic presynaptic terminals (Wu and Saggau, 1997), we tested whether presynaptic $\mathrm{GABA}_{\mathrm{B}} \mathrm{R}$-mediated inhibition could also cause $e$-LTD as the frequency of the spike-timing protocol increased. Application of the LTP-timing protocol (time intervals at the +4 to $+6 \mathrm{~ms}$ ), which normally induced $e$-LTP at the $\theta$ frequency (Figure 6A, top), had no significant effect on synaptic efficacy at $12 \mathrm{~Hz}$ ( $\alpha$ frequency, for $6.7 \mathrm{~s} ; 91.4 \pm 10.6 \%, n=6$, in the $\mathrm{Cs}^{+}$-based 
A $\operatorname{LTP}(+4$ to +6 msec $)$
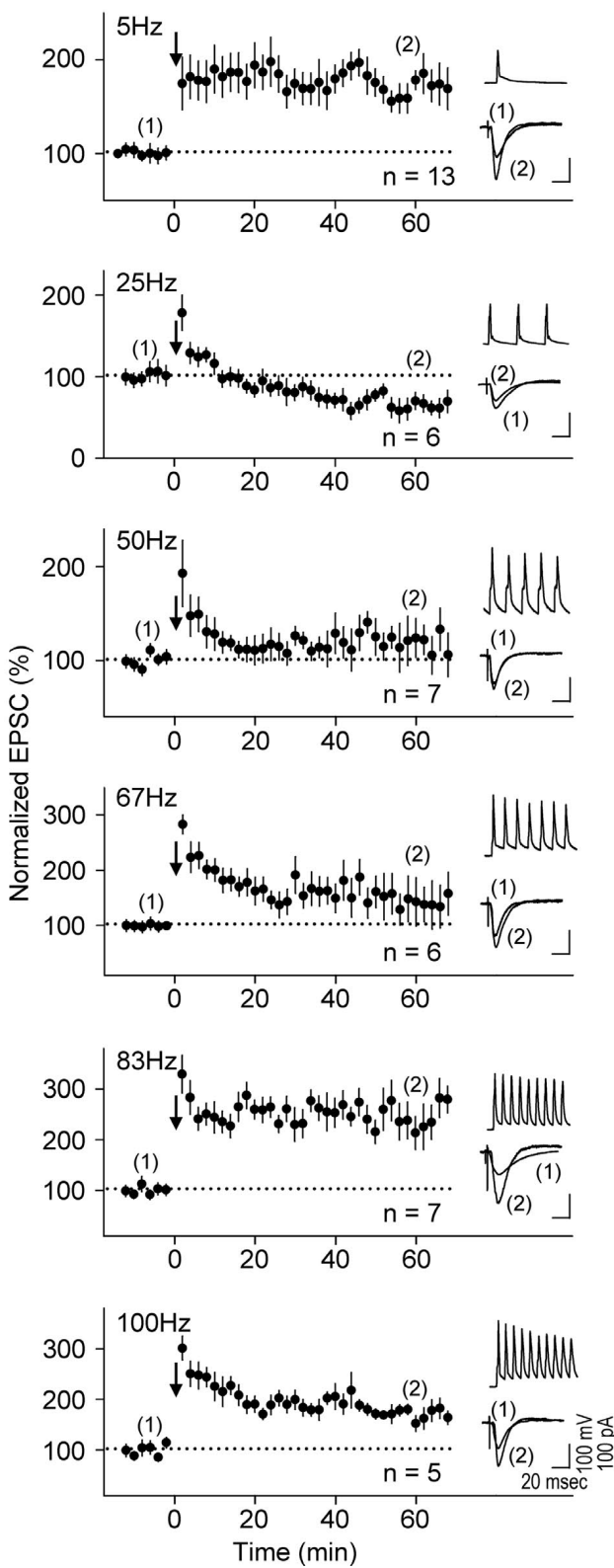

$$
\text { B }
$$
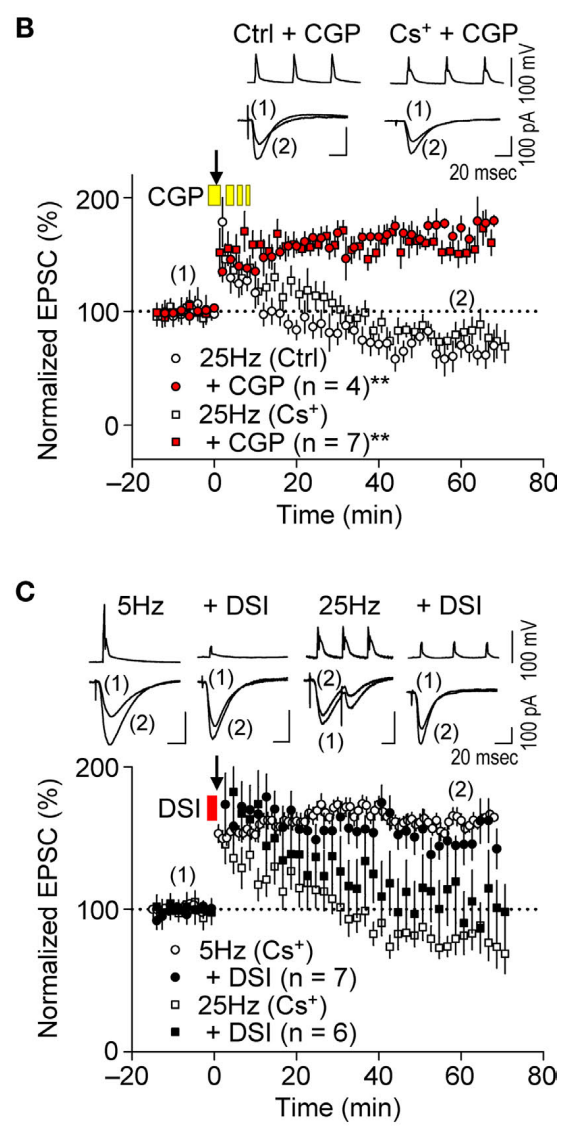

D

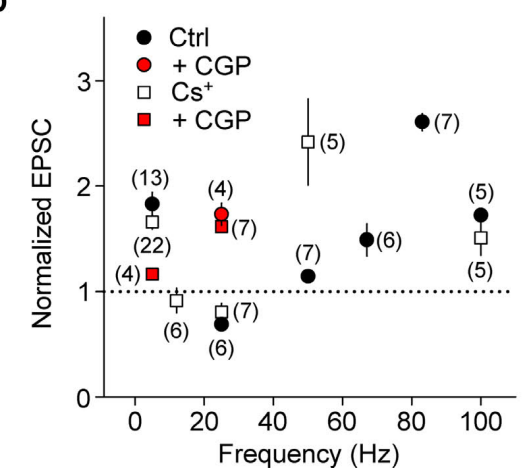

FIGURE 6 | Presynaptic GABA ${ }_{B}$ R-mediated inhibition causes frequencydependent $\boldsymbol{e}$-LTD at $\boldsymbol{\alpha} / \boldsymbol{\beta}$ frequencies. (A,D) Summary of frequency-dependent changes in synaptic efficacy induced by the spike-timing protocol for LTP-timing ( +4 to $+6 \mathrm{~ms}$ ). Frequency-dependent effects (between $5 \mathrm{~Hz}$ and $100 \mathrm{~Hz}$ ) in either the $\mathrm{K}^{+}$- or $\mathrm{Cs}^{+}$-based internal recording solution. Frequency-dependent e-LTD is induced at the same magnitude at $25 \mathrm{~Hz}$ and eLTP is robust at the $\gamma$ frequency in both recording solutions. (B) Bath application of CGP 35348 (1 mM, yellow bars)

internal solution; see Figure 6D). A further increase in the frequency of paired stimulation to $25 \mathrm{~Hz}$ ( $\beta$ frequency) resulted in $e$-LTD, not $e$-LTP, in both $\mathrm{K}^{+}$- and $\mathrm{Cs}^{+}$-based solutions. Furthermore, the most robust $e$-LTP was observed (substantially greater than that induced by the LTP-timing protocol at 5 and $100 \mathrm{~Hz}$ ) when the frequency of the LTP-timing protocol reached the $\gamma$ frequency $(50-80 \mathrm{~Hz})$ in both the $\mathrm{K}^{+}$- and $\mathrm{Cs}^{+}$-based internal solutions. However, the abolished e-LTD at $25 \mathrm{~Hz}$, and instead induced e-LTP in both $\mathrm{K}^{+}$- and the $\mathrm{Cs}^{+}$-based internal recording solutions. (C) DSI failed to restore e-LTP induction at $25 \mathrm{~Hz}$ and had no significant effect on e-LTP at $5 \mathrm{~Hz}$. Data represent normalized mean EPSCs ( \pm sem). Membrane potentials during the spike-timing protocol (upper traces) and EPSCs (lower traces) before (1) and after (2) the induction protocols (in A-C). Scales: 100 pA (or 100 mV), 20 ms. Significant differences from corresponding controls are indicated (“**” $p<0.01$; Mann-Whitney U test).

optimal frequency for induction of the maximal $e$-LTP in the $\mathrm{Cs}^{+}-$ based internal solution $(50 \mathrm{~Hz})$ appears to be lower than that in the $\mathrm{K}^{+}$-based internal solution $(83 \mathrm{~Hz})$. This may have resulted from the slower kinetics of EPSPs in the $\mathrm{Cs}^{+}$-based internal solution, which allows overlap with the preceding EPSPs to cause a postsynaptic depolarization, even at a lower frequency. It is noteworthy that during LTP induction at the $\gamma$ frequency the postsynaptic $G_{A B A} R$ 
function should be excitatory (Staley et al., 1995; Taira et al., 1997; Bracci et al., 2001), thereby likely enhancing the magnitude of $e$-LTP. These results support the idea that the induction of $e$-LTD also depends on the frequency of the spike-timing protocol, which is independent of postsynaptic $\mathrm{K}^{+}$channel function.

We examined further the effect of presynaptic $\mathrm{GABA}_{\mathrm{B}} \mathrm{R}$-mediated inhibition on the frequency-dependent induction of $e$-LTD by applying the $\mathrm{GABA}_{\mathrm{B}} \mathrm{R}$ antagonist CGP35348 $(1 \mathrm{mM}$, Davies and Collingridge, 1996) in the bath during the spike-timing protocol. This treatment abolished $e$-LTD induction at $25 \mathrm{~Hz}$ and resulted in a substantial $e$-LTP instead, in both $\mathrm{K}^{+}$- and $\mathrm{Cs}^{+}$-based solutions (Figures 6B,D), suggesting that $\mathrm{GABA}_{\mathrm{B}} \mathrm{R}$ function is required for the induction of this frequency-dependent $e$-LTD. Interestingly, CGP35348 suppressed $e$-LTP induction at $5 \mathrm{~Hz}$, the frequency at which presynaptic $\mathrm{GABA}_{\mathrm{B}} \mathrm{R}$ is most prominent at inhibitory inputs (Figure 6D, Davies and Collingridge, 1993), suggesting that postsynaptic $\mathrm{GABA}_{\mathrm{A}} \mathrm{R}$ function is enhanced as a consequence of this treatment. Bath application of phaclofen, another $G_{A B A} R$ antagonist, at the concentration $(100 \mu \mathrm{M})$ that blocks presynaptic $\mathrm{GABA}_{\mathrm{B}} \mathrm{R}$-mediated inhibition at excitatory (Hasselmo and Fehlau, 2001) but not at inhibitory (Davies and Collingridge, 1993) inputs during the spike-timing protocol, similarly converted the $e$-LTD to robust $e$-LTP at $25 \mathrm{~Hz}(178.0 \pm 17.4 \%, n=4)$. Thus, presynaptic $\mathrm{GABA}_{\mathrm{B}} \mathrm{R}$-mediated inhibition at excitatory synapses is likely responsible for the frequency-dependent expression of $e$-LTD. Consistent with the idea that presynaptic $\mathrm{GABA}_{\mathrm{B}} \mathrm{R}$-mediated inhibition, but not postsynaptic $\mathrm{GABA}_{\mathrm{A}} \mathrm{R}$-mediated inhibition, may be a major inducer of frequency-dependent $e$-LTD, DSI affected $e$-LTD at $25 \mathrm{~Hz}$ only partially, while it had no significant effect on $e$-LTP induction at $5 \mathrm{~Hz}$ (Figure 6C). This partial effect could be due to a reduction of GABA release by DSI (Lenz and Alger, 1999), which would also reduce presynaptic $\mathrm{GABA}_{\mathrm{B}} \mathrm{R}$-mediated inhibition. Taken together, these results suggest that presynaptic $\mathrm{GABA}_{\mathrm{B}} \mathrm{R}$-mediated inhibition controls the frequency dependence of $e$-LTD at $\alpha / \beta$ frequencies and accounts for the expression of $e$-LTP at $\theta$ and $\gamma$ frequencies.

\section{DISCUSSION}

We demonstrated that GABAergic interneuronal network activities control the spike timing- and frequency-dependent induction of the $e$-LTD (at -LTD and +LTD time intervals) that delineates the expression of $e$-LTP in hippocampal CA1 pyramidal cells (see Figure 7A). The timing dependence of $e$-LTD induced by the $\theta$ frequency spike-timing protocol is regulated by both $\mathrm{FF}$ and $\mathrm{FB}$ postsynaptic $\mathrm{GABA}_{\mathrm{A}} \mathrm{R}$-mediated inhibition. Feedback postsynaptic $\mathrm{GABA}_{\mathrm{A}} \mathrm{R}$-mediated inhibition enforces the cooperative induction of $e$-LTP by causing $e$-LTD from a small population of the SC inputs during the LTP-timing. In contrast, the frequency-dependent expression of $e$-LTD at $\alpha / \beta$ frequencies is regulated predominantly by presynaptic $\mathrm{GABA}_{\mathrm{B}} \mathrm{R}$-mediated inhibition. This $e$-LTD then segregates the expression of $e$-LTP into $\theta$ (timing-dependent) and $\gamma$ (timing-independent) frequencies. The induction of similar magnitudes of $e$-and $i$-STDP in hippocampal SC-CA1 networks further demonstrates a novel mechanism by which GABAergic inhibition actively causes the induction of $e$-LTD.

Previously, the timing dependence of $e$-STDP was extensively studied using a low-frequency $(<2 \mathrm{~Hz})$ spike-timing induction protocol in various systems (Bi and Poo, 1998; Debanne et al., 1998; Zhang et al.,
1998; Feldman, 2000; Froemke and Dan, 2002; Nevian and Sakmann, 2006). These studies led to the formulation of the asymmetric STDP learning rule: pre-before-post (causal order) results in $e$-LTP and postbefore-pre (anti-causal order) results in $e$-LTD at the negative time intervals. The asymmetric STDP learning rule, which is compatible with Hebbian synaptic plasticity (Bliss and Collingridge, 1993) has been applied to explain bidirectional neuronal functions. In contrast, stimulation at the $\theta$ frequency $(5 \mathrm{~Hz})$, as in our previous (Nishiyama et al., 2000) and current studies and those of others (Wittenberg and Wang, 2006), results in the induction of a second $e$-LTD time window at positive time intervals. Also, a low-frequency $(<2 \mathrm{~Hz})$ spike-timing protocol induces a relatively broad $e$-LTD time window $(>50 \mathrm{~ms})$ at negative time intervals, whereas $\theta$ frequency induction of the STDP protocol induces relatively narrow $e$-LTD time windows $(\sim 20 \mathrm{~ms})$ at both -LTD and +LTD. Although the mechanisms of the appearance of narrow windows and an additional +LTD stimulated by the $\theta$ frequency are not understood, we found that while-LTD is fully sensitive to postsynaptic $\mathrm{GABA}_{\mathrm{A}} \mathrm{R}$-mediated inhibition, $+\mathrm{LTD}$ is only partially sensitive (Wittenberg and Wang, 2006), suggesting the involvement of unidentified mechanisms other than postsynaptic $\mathrm{GABA}_{\mathrm{A}} \mathrm{R}$-mediated inhibition and mechanisms related to spike afterhyperpolarization that suppress postsynaptic $\mathrm{Ca}^{2+}$ increase. Interestingly, computational analyses predict the stable presence of +LTD if the number of postsynaptic NMDARs increases (Shouval and Kalantzis, 2005). In support of this idea, recent electron microscopy study using the freeze-fracture replica method (Shinohara et al., 2008) demonstrated a much greater number of NMDARs at the spines of CA1 pyramidal cells compared to that reported previously (Racca et al., 2000). The greater number of NMDARs may be attributable to the persistent presence of +LTD induced by the $\theta$ frequency spike-timing protocol. Alternatively, it is also plausible that in addition to the different frequency dependency of FB IPSC recruitment in cortical neurons (Silberberg and Markram, 2007), cortical neurons may be innately endowed with an asymmetric, not a symmetric, STDP learning rule by these low-frequency stimuli.

In the current study, we applied DSI to investigate the timing dependence of $e$-STDP. Surprisingly, the DSI procedure caused drastic effects on the induction of $e$-STDP, even though a relatively minor population of interneurons (Glickfeld and Scanziani, 2006) are expected to be sensitive to it. Endocannabinoid receptor CB1Rexpressing basket cells apparently receive inputs from both CA3 (the SC) and CA1 (the recurrent) pyramidal cells (Glickfeld and Scanziani, 2006). Therefore, these CB1R-expressing interneurons are highly likely to be involved in the determination of the timing dependence and the requirement for cooperative $e$-STDP by inducing both $\mathrm{FF}$ and $\mathrm{FB}$ postsynaptic $\mathrm{GABA}_{\mathrm{A}} \mathrm{R}$-mediated inhibition to the CA1 pyramidal cells during the spike-timing protocol. It has been demonstrated that burst postsynaptic spiking is required for $e$-LTP induction by $\theta$ frequency stimuli at SC-CA1 synapses (Thomas et al., 1998; Pike et al., 1999; Meredith et al., 2003; Wittenberg and Wang, 2006). In this case, the burst spiking, which is known to silence A-type $\mathrm{K}^{+}$channel activity in distal dendrites (Hoffman et al., 1997), likely facilitates the back-propagation of action potentials during the induction protocol. In our protocol, however, repetitive single (no burst) postsynaptic spiking is sufficient to induce $e$-LTP (Nishiyama et al., 2000), suggesting that the activated synapses are distant from functional A-type channels (Hoffman et al., 1997). 
$\mathbf{A}$

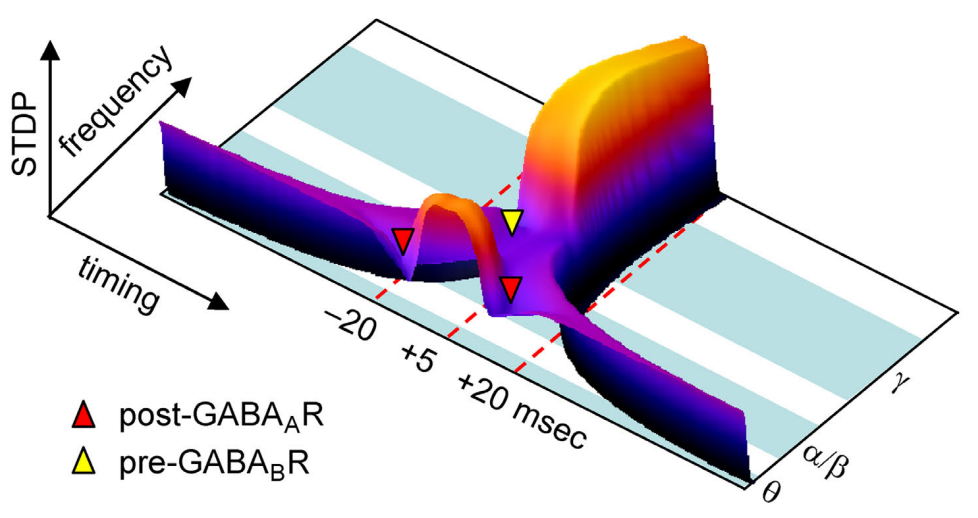

B

\section{LTP-time interval}

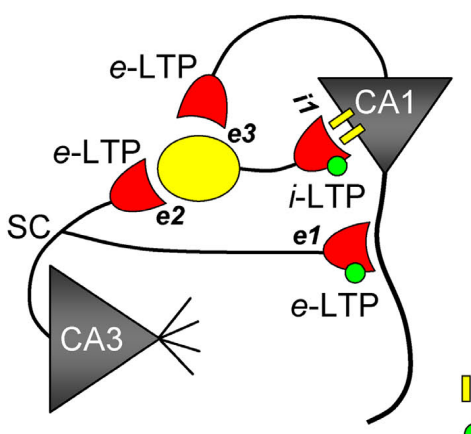

\section{LTD-time interval}

\section{0 post-GABA pre-GABA $\operatorname{CB} 1 R(+)$ interneuron}

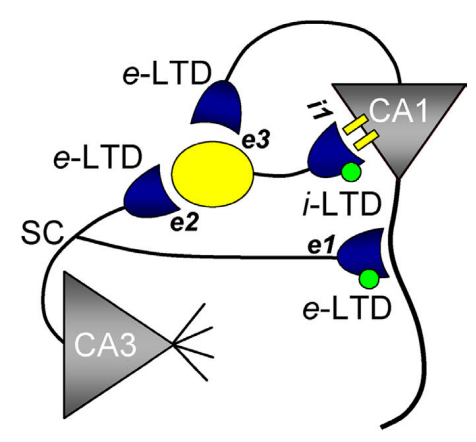

(right) protocol at $5 \mathrm{~Hz}$, all excitatory synapses undergo, respectively, either e-LTP or e-LTD. e-LTP or e-LTD in the CB1R-expressing interneuron (both at inputs $e 2$ and e3) propagates passively to input $i-1$, respectively, as either $i$-LTP or $i$-LTD.
FIGURE 7 | Model for STDP controlled by GABA functions in the CA1 network. (A) Both spike timing- and frequency-dependence of e-STDP and differential GABA function that gates e-LTD. (B) Parallel induction of e-LTP/i-LTP and e-LTD/i-LTD. Upon application of the LTP- (left) or LTD-timing that postsynaptic spikes broadened by $\mathrm{Cs}^{+}$do not contribute significantly to the features of $e$-STDP. This may also be consistent with the idea that $\mathrm{Ca}^{2+}$ entry through VDCCs is not essential for the induction of $e$-LTP (Bi and Poo, 1998) and $e$-LTD (Nishiyama et al., 2000). Our experimental paradigm is, thus, a unique procedure for the investigation of GABAergic activities during STDP. It has been shown that local dendritic spikes, without back-propagating action potentials, cause the induction of $e$-LTP (Golding et al., 2002). This type of synaptic plasticity is prominent at synaptic inputs of distal dendrites, where A-type channels prohibit invasion of single back-propagating action potentials (Hoffman et al., 1997). Our study, however, reveals the existence of bidirectional synaptic plasticity at proximal synaptic inputs that relies on the timing of single back-propagating action potentials. Depending on the location (i.e., proximal or distal dendrites) of activated synapses, different types of induction mechanisms, therefore, may be required to determine bidirectional synaptic plasticity. with those in a $\mathrm{K}^{+}$-base internal solution and found a broad spike width in the $\mathrm{Cs}^{+}$-based internal solution. However, it appears 
Using weak SC input stimuli, we demonstrated that FB postsynaptic $\mathrm{GABA}_{\mathrm{A}} \mathrm{R}$-mediated inhibition enforces the cooperative requirement for LTP induction (i.e., EPSC amplitude of $>70 \mathrm{pA}$ ). However, we cannot exclude the following possibilities: The DSI procedure may diminish the postsynaptic $\mathrm{GABA}_{\mathrm{A}} \mathrm{R}$-mediated actions by one half, including tonic inhibition (Mody and Pearce, 2004). Thus, the actual EPSC amplitude during the LTP-timing protocol (i.e., EPSP amplitude) may become greater than $70 \mathrm{pA}$ as a result of the diminished shunting effect. Since, in our preparation, the EPSP amplitude is below $1 \mathrm{mV}$ when the EPSC amplitude is smaller than $70 \mathrm{pA}$, it is not possible to accurately assess changes in EPSP amplitudes during the spike-timing protocol if they increased above the amplitude equivalent to EPSCs of $70 \mathrm{pA}$. We did not observe noticeable differences in the EPSP amplitudes in the presence of DSI compared to the control (data not shown). Moreover, the DSI permits induction of robust LTP, even at inputs with initial EPSC amplitudes of less than 40 pA (see Figure 4B). Therefore, DSI is unlikely to have caused increases of the actual EPSP during the spike-timing protocol. We demonstrated the absence of functional FF-IPSCs when the EPSC amplitude was less than $70 \mathrm{pA}$ with the use of single stimuli at SC inputs. However, in response to sequential stimuli, such as during the spike-timing protocol, FF-IPSCs may become manifest due to sequential pulse facilitation, particularly in interneurons that receive both SC and recurrent inputs. Even if a potential contamination from FF-IPSCs occurs, it is likely negligible compared to the prominent FB-IPSCs (an IPSP amplitude of ca. $-34 \mathrm{mV}$, which is equivalent to an IPSC amplitude of ca. 800 to $900 \mathrm{pA}$ ). Therefore, our conclusion that FB postsynaptic $\mathrm{GABA}_{\mathrm{A}} \mathrm{R}-$ mediated inhibition enforces the cooperative requirement for LTP induction would not be affected significantly.

We showed that FF-IPSCs undergo $i$-LTP and $i$-LTD, which are associated, respectively, with $e$-LTP and $e$-LTD induced by the $\theta$ frequency spike-timing protocol at SC-CA1 excitatory synapses. Two distinct mechanisms, passive and active induction, that cause synaptic efficacy changes in excitatory inputs to interneurons have been demonstrated. Both $e$-LTP and $e$-LTD propagate passively to FB interneurons (Maccaferri and McBain, 1995, 1996). Interneurons also express e-LTP directly (Kullmann and Lamsa, 2007) at the SC input (Lamsa et al., 2005) and at the input from CA1 pyramidal cells (Lamsa et al., 2007). Interestingly, $e$-LTP at the SC-FF interneuron synapses propagates to the inhibitory input to CA1 pyramidal cells (Lamsa et al., 2005). The parallel induction of $e$-LTP/ $i$-LTP and $e$-LTD/ $i$-LTD that we observed may, therefore, depend on both the passive and active mechanisms of induction of inhibitory synaptic plasticity (Figure 7B). Since CB1R-expressing basket cells (Glickfeld and Scanziani, 2006) receive inputs from both CA 3 and from the recorded CA1 pyramidal cells, the magnitudes of which are each sufficient to spike these interneurons, both $e$-LTP and $e$-LTD can be induced. These excitatory inputs to interneurons may follow a similar STDP learning rule for excitatory inputs to recorded CA1 pyramidal cells. During the LTP-timing protocol, the disynaptic inputs from CA3 and CA1 should be the LTP-timing for one another (i.e., time intervals of $\sim 0 \mathrm{~ms}$ ). Conversely, during the LTD-timing protocol, these inputs become either the +LTD or -LTD time intervals for one another, because the time difference between two inputs to an interneuron is approximately $20 \mathrm{~ms}$, which is the LTD time interval. Therefore, upon application of the spike-timing protocol, excitatory inputs to both CA1 recording cells and interneurons undergo $e$-STDP with the same polarity. Then, either $e$-LTP or $e$-LTD in interneurons propagates passively to inputs to CA1 recording cells to become, respectively, either $i$-LTP or $i$-LTD. Thus, the parallel induction of $e$ - and $i$-LTP may help to maintain the temporal resolution of excitatory synaptic integration and the generation of an action potential in excitatory LTP-expressing CA1 pyramidal cells (Pouille and Scanziani, 2001; Lamsa et al., 2005).

We also showed that the frequency dependence of $e$-LTD at $\alpha / \beta$ frequencies, which likely delineates the expression of $e$-LTP at the $\theta$ and $\gamma$ frequencies, requires presynaptic $\mathrm{GABA}_{\mathrm{B}} \mathrm{R}$-mediated inhibition. This is consistent with the optimal frequencies required for induction of presynaptic $\mathrm{GABA}_{\mathrm{B}} \mathrm{R}$-mediated inhibition, which are maximal at the $\theta$ and above the $\alpha / \beta$ frequencies for inhibitory and excitatory presynaptic terminals, respectively (Davies and Collingridge, 1996; Ohliger-Frerking et al., 2003). In addition to the appearance of $e$-LTD at $\alpha / \beta$ frequencies, we observed that the magnitude of $e$-LTP begins to decrease if the frequency of the spike-timing protocol increases above the $\gamma$ frequency (i.e., at $100 \mathrm{~Hz}$ ). Although the molecular mechanisms underlying the reduction of $e$-LTP at a high frequency requires further investigation, its non-linearity apparently violates $\mathrm{Ca}^{2+}$ theory for synaptic plasticity. Despite this, our study demonstrates that $e$-STDP in CA1 pyramidal cells is likely self-limited by the neural network function. It has been reported that postsynaptic $\mathrm{GABA}_{\mathrm{B}}$ Rs inactivate VDCCs independent of GIRK activity (Perez-Garci et al., 2006). However, since $e$-LTD at the $\theta$ frequency appears to be independent of VDCC activity (Nishiyama et al., 2000), postsynaptic GABA $_{\mathrm{B}}$ Rs may not be involved in $e$-LTD induction. The potential contribution of postsynaptic $\mathrm{GABA}_{\mathrm{B}} \mathrm{R}$-mediated inhibition to frequency-dependent $e$-LTD at the $\alpha / \beta$ frequencies requires further investigation.

Taken together, our study demonstrates the mechanism by which GABAergic inhibitory activities cause $e$-LTD at time intervals of $\pm 20 \mathrm{~ms}$ (at the $\theta$ frequency) or at $\alpha / \beta$ frequencies to control the timing- and frequency-dependent features of $e$-STDP; $e$-LTP/eLTD switches within the $\gamma$ cycle (Nishiyama et al., 2000) and $e$-LTP appears at the $\theta$ and $\gamma$ frequencies. Therefore, the GABAergic interneuronal network activities that regulate STDP may similarly govern hippocampal oscillations in vivo (Buzsáki, 2002; Csicsvari et al., 2003; Lisman et al., 2005). Interestingly, the parallel induction of STDP demonstrated in this study, in which $e$-LTP likely depolarizes dendrites when $i$-LTP hyperpolarizes the soma, is consistent with the in vivo hippocampal $\theta$ oscillation that yields a phase-shift, a current sink at the dendrite and a current source at the soma resulting from GABAergic and cholinergic activities (Kamondi et al., 1998; Buzsáki, 2002). Future studies will determine whether the underlying mechanisms of GABAergic interneuronal network activities that govern STDP also apply to $\theta$ and $\gamma$ oscillations.

\section{ACKNOWLEDGMENTS}

This work was supported by the CRCNS program NSF/NIH (MH068027), the Whitehall Foundation Inc. and the Brain Science Foundation. We thank Drs. M. M. Poo, D. Debanne, H. Eichenbaum, B. H. Gaehwiler, J. E. Lisman, N. Spruston and H. Sei for discussion and comments; W. Jelinek and N. Cowen for critical comments on the manuscript; K. Kato for technical support. 


\section{REFERENCES}

Bartos, M., Vida, I., and Jonas, P. (2007). Synaptic mechanisms of synchronized gamma oscillations in inhibitory interneuron networks. Nat. Rev. Neurosci. 8, 45-56.

Bi, G.-q., and Poo, M.-m. (1998). Synaptic modifications in cultured hippocampal neurons: dependence on spike timing, synaptic strength, and postsynaptic cell type. J. Neurosci. 18, 10464-10472.

Bliss, T. V., and Collingridge, G. L. (1993). A synaptic model of memory: longterm potentiation in the hippocampus. Nature 361, 31-39.

Bracci, E., Vreugdenhil, M., Hack, S. P., and Jefferys, J. G. R. (2001). Dynamic modulation of excitation and inhibition during stimulation at gamma and beta frequencies in the CA1 hippocampal region. J. Neurophysiol. 85, 2412-2422.

Buzsáki, G. (2002). Theta oscillations in the hippocampus. Neuron 33, 325-340.

Buzsáki, G., Penttonen, M., Nádasdy, Z., and Bragin, A. (1996). Pattern and inhibition-dependent invasion of pyramidal cell dendrites by fast spikes in the hippocampus in vivo. Proc. Natl. Acad. Sci. U.S.A. 93, 9921-9925.

Caporale, N., and Dan, Y. (2008). Spike timing-dependent plasticity: a Hebbian learning rule. Annu. Rev. Neurosci. 31, 25-46.

Cardin, J. A., Carlén, M., Meletis, K., Knoblich, U., Zhang, F., Deisseroth, K., Tsai, L. H., and Moore, C. I. (2008). Driving fast-spiking cells induces gamma rhythm and controls sensory responses. Nature 459, 663-667.

Carlson, G., Wang, Y., and Alger, B. (2002). Endocannabinoids facilitate the induction of LTP in the hippocampus. Nat. Neurosci. 5, 723-724.

Chevaleyre, V., and Castillo, P. (2003). Heterosynaptic LTD of hippocampal GABAergic synapses: a novel role of endocannabinoids in regulating excitability. Neuron 38, 461-472.

Chevaleyre, V., and Castillo, P. (2004). Endocannabinoid-mediated metaplasticity in the hippocampus. Neuron 43, 871-881.

Connors, B. W., Malenka, R. C., and Silva, L. R. (1988). Two inhibitory postsynaptic potentials, and $\mathrm{GABA}_{\mathrm{A}}$ and $\mathrm{GABA}_{\mathrm{B}}$ receptor-mediated responses in neocortex of rat and cat. J. Physiol. 406, 443-468.

Csicsvari, J., Jamieson, B., Wise, K., and Buzsáki, G. (2003). Mechanisms of gamma oscillations in the hippocampus of the behaving rat. Neuron 37, 311-322.

Dan, Y., and Poo, M.-M. (2006). Spike timing-dependent plasticity: from synapse to perception. Physiol. Rev. 86, 1033-1048.

Davies, C. H., and Collingridge, G. L. (1993). The physiological regulation of synaptic inhibition by GABA autoreceptors in rat hippocampus. J. Physiol. 472, 245-265.

Davies, C. H., and Collingridge, G. L. (1996). Regulation of EPSPs by the synaptic activation of $\mathrm{GABA}_{\mathrm{B}}$ autoreceptors in rat hippocampus. J. Physiol. 496, 451-470.

Debanne, D., Gahwiler, B. H., and Thompson, S. M. (1998). Long-term synaptic plasticity between pairs of individual CA3 pyramidal cells in rat hippocampal slice cultures. J. Physiol. 507, 237-247.

Feldman, D. (2000). Timing-based LTP and LTD at vertical inputs to layer II/ III pyramidal cells in rat barrel cortex. Neuron 27, 45-56.

Froemke, R., and Dan, Y. (2002). Spiketiming-dependent synaptic modification induced by natural spike trains. Nature 416, 433-438.

Gibson, H. E., Edwards, J. G., Page, R. S., Van Hook, M. J., and Kauer, J. A. (2008). TRPV1 channels mediate long-term depression at synapses on hippocampal interneurons. Neuron 57, 746-759.

Glickfeld, L. L., and Scanziani, M. (2006). Distinct timing in the activity of cannabinoid-sensitive and cannabinoidinsensitive basket cells. Nat. Neurosci. 9, 807-815.

Golding, N., Staff, N., and Spruston, N. (2002). Dendritic spikes as a mechanism for cooperative long-term potentiation. Nature 418, 326-331.

Hasselmo, M. E., and Fehlau, B. P. (2001). Differences in time course of ACh and GABA modulation of excitatory synaptic potentials in slices of rat hippocampus. J. Neurophysiol. 86, 1792-1802.

Hoffman, D., Magee, J., Colbert, C., and Johnston, D. (1997). $\mathrm{K}^{+}$channel regulation of signal propagation in dendrites of hippocampal pyramidal neurons. Nature 387, 869-875.

Isokawa, M., and Alger, B. E. (2006). Ryanodine receptor regulates endogenous cannabinoid mobilization in the hippocampus. J. Neurophysiol. 95, 3001-3011.

Jarsky, T., Roxin, A., Kath, W. L., and Spruston, N. (2005). Conditional dendritic spike propagation following distal synaptic activation of hippocampal CA1 pyramidal neurons. Nat. Neurosci. 8, 1667-1676.

Kamondi, A., Acsady, L., Wang, X., and Buzsáki, G. (1998). Theta oscillations in somata and dendrites of hippocampal pyramidal cells in vivo: activity-dependent phase-precession of action potentials. Hippocampus 8 244-261.

Kato, K., Clark, G. D., Bazan, N. G., and Zorumski, C. F. (1994). Plateletactivating factor as a potential retrograde messenger in CA1 hippocampal long-term potentiation. Nature 367 175-179.

Klausberger, T., and Somogyi, P. (2008). Neuronal diversity and temporal dynamics: the unity of hippocampal circuit operations. Science 321, 53-57.

Koester, H. J., and Sakmann, B. (1998). Calcium dynamics in single spines during coincident pre- and postsynaptic activity depend on relative timing of back-propagating action potentials and subthreshold excitatory postsynaptic potentials. Proc. Natl. Acad. Sci. U.S.A. 95, 9596-9601.

Kullmann, D. M., and Lamsa, K. P. (2007) Long-term synaptic plasticity in hippocampal interneurons. Nat. Rev Neurosci. 8, 687-699.

Lamsa, K., Heeroma, J., and Kullmann, D. (2005). Hebbian LTP in feed-forward inhibitory interneurons and the temporal fidelity of input discrimination. Nat. Neurosci. 8, 916-924.

Lamsa, K. P., Heeroma, J. H., Somogyi, P., Rusakov, D. A., and Kullmann, D. M. (2007). Anti-Hebbian long-term potentiation in the hippocampal feedback inhibitory circuit. Science $315,1262-1266$.

Lenz, R. A., and Alger, B. (1999). Calcium dependence of depolarization-induced suppression of inhibition in rat hippocampal CA1 pyramidal neurons. J. Physiol. 521, 147-157.

Lisman, J., Talamini, L., and Raffone, A (2005). Recall of memory sequences by interaction of the dentate and CA3 a revised model of the phase precession. Neural. Netw. 18, 1191-1201.

Maccaferri, G., David, J., Roberts, B., Szucs, P., Cottingham, C. A., and Somogyi, P. (2000). Cell surface domain specific postsynaptic currents evoked by identified GABAergic neurones in rat hippocampus in vitro. J. Physiol. 524, 91-116.

Maccaferri, G., and McBain, C. J. (1995). Passive propagation of LTD to stratum oriens-alveus inhibitory neurons modulates the temporoammonic input to the hippocampal CA1 region. Neuron 15, 137-145.

Maccaferri, G., and McBain, C. J. (1996) Long-term potentiation in distinct subtypes of hippocampal nonpyramidal neurons. J. Neurosci. 16, 5334-5343.

Magee, J. C., and Johnston, D. (1997). A synaptically controlled, associative signal for Hebbian plasticity in hippocampal neurons. Science 275 209-213.
Markram, H., Lübke, J., Frotscher, M and Sakmann, B. (1997). Regulation of synaptic efficacy by coincidence of postsynaptic APs and EPSPs. Science 275, 213-215.

McMahon, L. L., and Kauer, J. A. (1997). Hippocampal interneurons express a novel form of synaptic plasticity. Neuron 18, 295-305.

Megias, M., Emri, Z., Freund, T., and Gulyas, A. (2001). Total number and distribution of inhibitory and excitatory synapses on hippocampal CA1 pyramidal cells. Neuroscience 102, 527-540.

Meredith, R. M., Floyer-Lea, A. M., and Paulsen, O. (2003). Maturation of long-term potentiation induction rules in rodent hippocampus: role of GABAergic inhibition. J. Neurosci.23, 11142-11146.

Mody, I., and Pearce, R. A. (2004). Diversity of inhibitory neurotransmission through GABA receptors. Trends Neurosci. 27, 569-575.

Nevian, T., and Sakmann, B. (2006). Spine $\mathrm{Ca}_{2}{ }^{+}$signaling in spike-timingdependent plasticity. J. Neurosci. 26, 11001-11013.

Nishiyama, M., Hong, K., Mikoshiba, K., Poo, M., and Kato, K. (2000). Calcium stores regulate the polarity and input specificity of synaptic modification. Nature 408, 584-588.

Normann, C., Peckys, D., Schulze, C. H. Walden, J., Jonas, P., and Bischofberger, J. (2000).Associative long-term depression in the hippocampus is dependent on postsynaptic $\mathrm{N}$-type $\mathrm{Ca} 2^{+}$channels. J. Neurosci. 20, 8290-8297.

Ohliger-Frerking, P., Wiebe, S. P., Stäubli, U., and Frerking, M. (2003). GABA receptor-mediated presynaptic inhibition has history-dependent effects on synaptic transmission during physiologically relevant spike trains. J. Neurosci. 23, 4809-4814.

Perez-Garci, E., Gassmann, M., Bettler, B., and Larkum, M. (2006). The GABA $1 \mathrm{~b}$ isoform mediates long-lasting inhibition of dendritic $\mathrm{Ca}^{+}$spikes in layer 5 somatosensory pyramidal neurons. Neuron 50, 603-616.

Petersen, C. C., Malenka, R. C., Nicoll, R. A., and Hopfield, J. J. (1998). Allor-none potentiation at CA3-CA1 synapses. Proc. Natl. Acad. Sci. U.S.A 95, 4732-4737.

Pike, F. G., Meredith, R. M., Olding, A. W., and Paulsen, O. (1999). Rapid report: postsynaptic bursting is essential for 'Hebbian' induction of associative long-term potentiation at excitatory synapses in rat hippocampus. $J$. Physiol. 518, 571-576.

Pouille, F., and Scanziani, M. (2001) Enforcement of temporal fidelity in pyramidal cells by somatic 
feed-forward Inhibition. Science 293, 1159-1163.

Pouille, F., and Scanziani, M. (2004). Routing of spike series by dynamic circuits in the hippocampus. Nature 429, 717-723.

Racca, C., Stephenson, F. A., Streit, P., Roberts, J. D., and Somogyi, P. (2000). NMDA receptor content of synapses in stratum radiatum of the hippocampal CA1 area. J. Neurosci. 20, 2512-2522.

Rumsey, C. C., and Abbott, L. F. (2006). Synaptic democracyin active dendrites. J. Neurophysiol. 96, 2307-2318.

Schiller, J., Major, G., Koester, H. J., and Schiller, Y. (2000). NMDA spikes in basal dendrites of cortical pyramidal neurons. Nature 404, 285-289.

Schiller, J., Schiller, Y., and Clapham, D. (1998). NMDA receptors amplify calcium influx into dendritic spines during associative pre- and postsynaptic activation. Nat. Neurosci. 1, 114-118.

Shinohara, Y., Hirase, H., Watanabe, M., Itakura, M., Takahashi, M., and Shigemoto, R. (2008). Left-right asymmetry of the hippocampal synapses with differential subunit allocation of glutamate receptors. Proc. Natl. Acad. Sci. U.S.A. 105, 19498-19503.

Shouval, H. Z., and Kalantzis, G. (2005). Stochastic properties of synaptic transmission affect the shape of spike time-dependent plasticity curves. $J$. Neurophysiol. 93, 1069-1073.
Silberberg, G., and Markram, H. (2007). Disynaptic inhibition between neocortical pyramidal cells mediated by Martinotti cells. Neuron 53, 735-746.

Sjöström, P., and Nelson, S. (2002). Spike timing, calcium signals and synaptic plasticity. Curr. Opin. Neurobiol. 12, 305-314.

Sjöström, P., Turrigiano, G., and Nelson, S. (2001). Rate, timing, and cooperativity jointly determine cortical synaptic plasticity. Neuron 32, 1149-1164.

Sjöström, P. J., and Häusser, M. (2006). A cooperative switch determines the sign of synaptic plasticity in distal dendrites of neocortical pyramidal neurons. Neuron 51, 227-238.

Sohal, V. S., Zhang, F., Yizhar, O., and Deisseroth, K. (2008). Parvalbumin neurons and gamma rhythms enhance cortical circuit performance. Nature 459, 698-702.

Staley, K., Soldo, B., and Proctor, W. (1995). Ionic mechanisms of neuronal excitation by inhibitory $\mathrm{GABA}_{\mathrm{A}}$ receptors. Science 269, 977-981.

Stuart, G., and Häusser, M. (2001). Dendritic coincidence detection of EPSPs and action potentials. Nat. Neurosci. 4, 63-71.

Taira, T., Lamsa, K., and Kaila, K. (1997). Posttetanic excitation mediated by GABA receptors in rat CA1 pyramidal neurons. J. Neurophysiol. 77, 2213-2218.
Thomas, M. J., Watabe, A. M., Moody, T. D., Makhinson, M., and O'Dell, T. J. (1998). Postsynaptic complex spike bursting enables the induction of LTP by theta frequency synaptic stimulation. J. Neurosci. 18, 7118-7126.

Tsubokawa, H., and Ross, W. N. (1996) IPSPs modulate spike backpropagation and associated $\left[\mathrm{Ca}^{+}\right]$i changes in the dendrites of hippocampal CA1 pyramidal neurons. J. Neurophysiol. 76, 2896-2906.

van Rossum, M. C., Bi, G. Q., and Turrigiano, G. G. (2000). Stable Hebbian learning from spike timingdependent plasticity. J. Neurosci. 20, 8812-8821.

Vargas-Caballero, M., and Robinson, H.P. (2004). Fast and slow voltage-dependent dynamics of magnesium block in the NMDA receptor: the asymmetric trapping block model. J. Neurosci. 24 6171-6180.

Whittington, M., Traub, R., and Jefferys, J. (1995). Synchronized oscillations in interneuron networks driven by metabotropic glutamate receptor activation. Nature 373, 612-615.

Wittenberg, G. M., and Wang, S. S.-H. (2006). Malleability of spike-timingdependent plasticity at the CA3-CA1 synapse. J. Neurosci. 26, 6610-6617.

Woodin, M., Ganguly, K., and Poo, M. (2003). Coincident pre- and postsynaptic activity modifies GABAergic synapses by postsynaptic changes in
Cl- transporter activity. Neuron 39, 807-820.

Wu, L., and Saggau, P. (1997). Presynaptic inhibition of elicited neurotransmitter release. Trends Neurosci. 20, 204-212.

Zhang, L., Tao, H., Holt, C., Harris, W., and Poo, M. (1998). A critical window for cooperation and competition among developing retinotectal synapses. Nature 395, 37-44.

Conflict of Interest Statement: The authors declare that the research was conducted in the absence of any commercial or financial relationships that could be construed as a potential conflict of interest.

Received: 12 March 2010; paper pending published: 23 April 2010; accepted: 30 May 2010; published online: 23 June 2010.

Citation: Nishiyama M, Togashi K, Aihara T and Hong K (2010) GABAergic activities control spike timing-and frequency-dependent long-term depression at hippocampal excitatory synapses. Front. Syn. Neurosci. 2:22. doi: 10.3389/ fnsyn.2010.00022

Copyright (c) 2010 Nishiyama, Togashi, Aihara and Hong. This is an open-access article subject to an exclusive license agreement between the authors and the Frontiers Research Foundation, which permits unrestricted use, distribution, and reproduction in any medium, provided the original authors and source are credited. 